Florida International University FIU Digital Commons

6-12-2014

\title{
Quantitative Analysis and Determination of Microcystin in water by Capillary Electrophoresis Mass Spectrometry
}

Bingxue Zheng

bzhen003@fiu.edu

DOI: $10.25148 /$ etd.FI14071176

Follow this and additional works at: https://digitalcommons.fiu.edu/etd

\section{Recommended Citation}

Zheng, Bingxue, "Quantitative Analysis and Determination of Microcystin in water by Capillary Electrophoresis Mass Spectrometry" (2014). FIU Electronic Theses and Dissertations. 1538.

https://digitalcommons.fiu.edu/etd/1538 


\title{
FLORIDA INTERNATIONAL UNIVERSITY
}

Miami, Florida

\section{QUANTITATIVE ANALYSIS AND DETERMINATION OF MICROCYSTIN IN}

WATER BY CAPILLARY ELECTROPHORESIS MASS SPECTROMETRY

\author{
A thesis submitted in partial fulfillment of \\ the requirements for the degree of \\ MASTER OF SCIENCE \\ in \\ CHEMISTRY \\ by
}

Bingxue Zheng 
To: Interim Dean Michael R. Heithaus College of Arts and Sciences

This thesis, written by Bingxue Zheng, and entitled Quantitative Analysis and Determination of Microcystin in Water by Capillary Electrophoresis Mass Spectrometry, having been approved in respect to style and intellectual content, is referred to you for judgment.

We have read this thesis and recommend that it be approved.

Yuk-Ching Tse-Dinh

Bruce McCord

John Berry, Major Professor

Date of Defense: June 12, 2014

The thesis of Bingxue Zheng is approved.

Interim Dean Michael R. Heithaus

College of Arts and Sciences

Dean Lakshmi N. Reddi

University Graduate School

Florida International University, 2014 


\begin{abstract}
OF THE THESIS
QUANTITATIVE ANALYSIS AND DETERMINATION OF MICROCYSTIN IN WATER BY CAPILLARY ELECTROPHORESIS MASS SPECTROMETRY
\end{abstract}

by

Bingxue Zheng

Florida International University, 2014

Miami, Florida

Professor John Berry, Major Professor

The presence of harmful algal blooms (HAB) is a growing concern in aquatic environments. Among HAB organisms, cyanobacteria are of special concern because they have been reported worldwide to cause environmental and human health problem through contamination of drinking water. Although several analytical approaches have been applied to monitoring cyanobacteria toxins, conventional methods are costly and time-consuming so that analyses take weeks for field sampling and subsequent lab analysis. Capillary electrophoresis (CE) becomes a particularly suitable analytical separation method that can couple very small samples and rapid separations to a wide range of selective and sensitive detection techniques. This paper demonstrates a method for rapid separation and identification of four microcystin variants commonly found in aquatic environments. CE coupled to UV and electrospray ionization time-of-flight mass spectrometry (ESI-TOF) procedures were developed. All four analytes were separated within 6 minutes. The ESI-TOF experiment provides accurate molecular information, which further identifies analytes. 


\section{TABLE OF CONTENTS}

CHAPTER

PAGE

\section{Background}

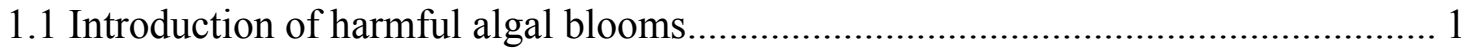

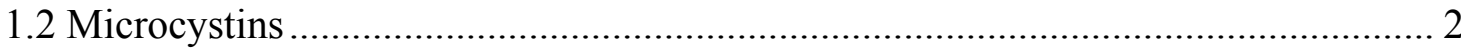

1.3 Mechanisms of MC toxicity ............................................................................... 4

1.4 Determination of $\mathrm{MC}$ with high performance liquid chromatography .................... 6

1.5 Determination of microcystins using capillary electrophoresis ............................ 8

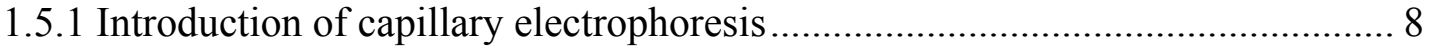

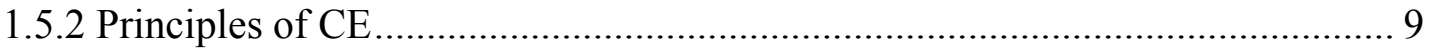

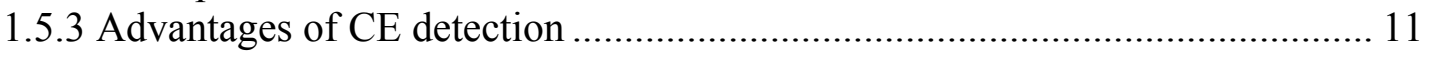

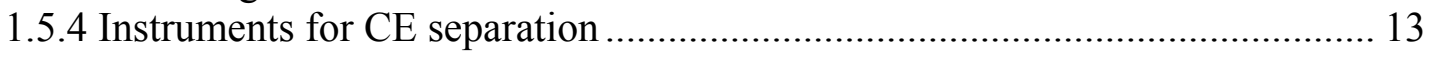

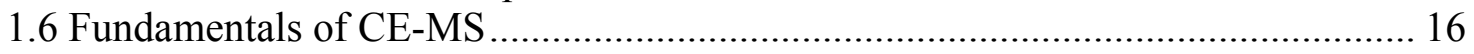

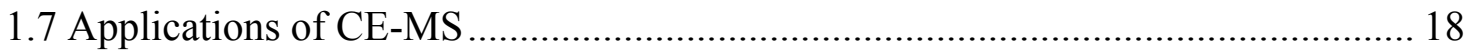

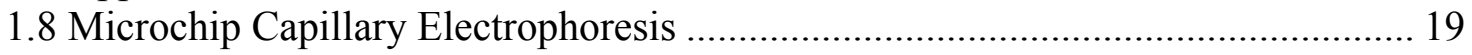

2 Materials and Methods

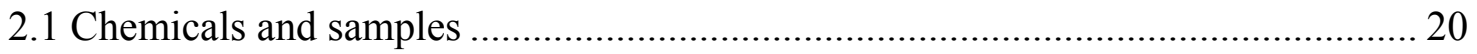

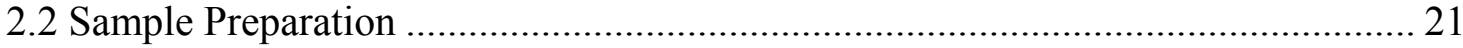

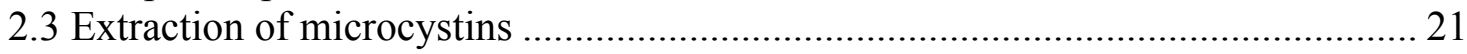

$2.4 \mathrm{CE}$ instruments and separation conditions ..................................................... 22

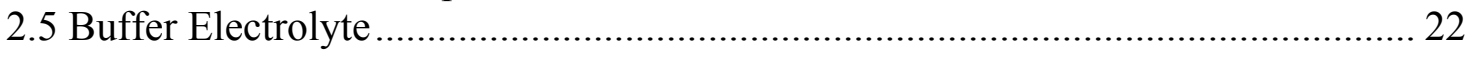

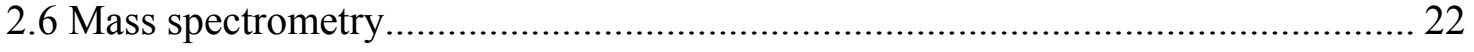

3 Results and discussion

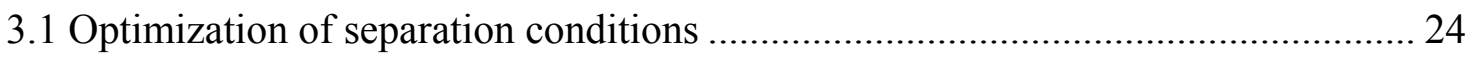

3.1.1 Selection of cyclodextrin as additive in buffer electrolyte ........................... 25

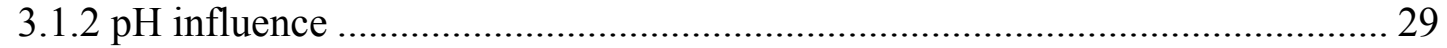

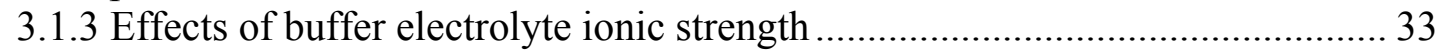

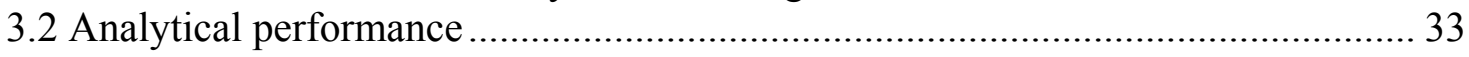

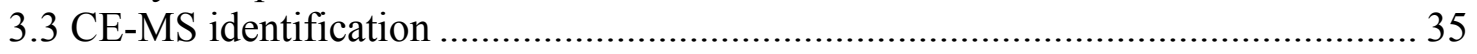

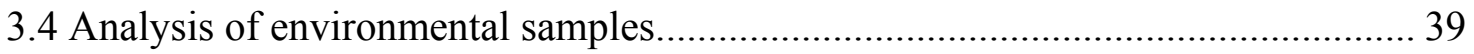

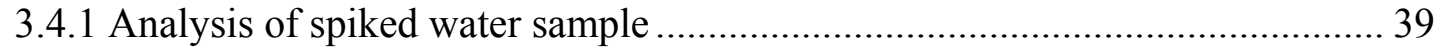

3.4.2 Analysis of unknown environmental sample ......................................... 40

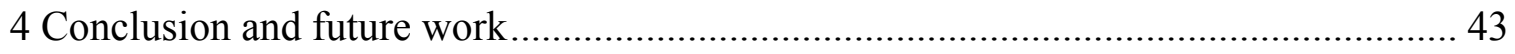

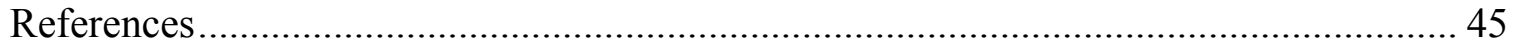




\section{LIST OF FIGURES}

FIGURE

PAGE

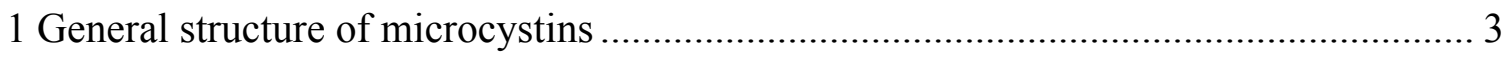

2 Schematic diagram of microcystin binding with PP 1 ........................................ 6

3 Formation of EOF inside of the capillary tube .................................................... 11

4 Flow velocity profiles and their resulting chromatograms .................................... 12

5 Elution of ions and neutral molecules under EOF ............................................... 13

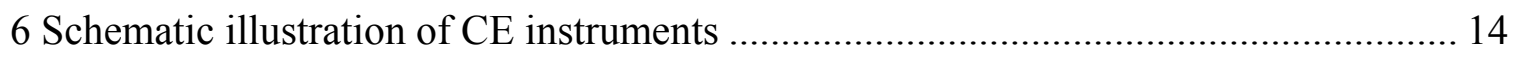

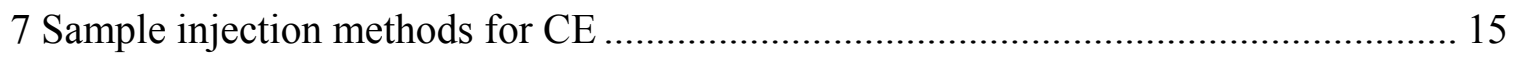

8 Tri-axial capillary sprayer used in sheath flow interface ....................................... 18

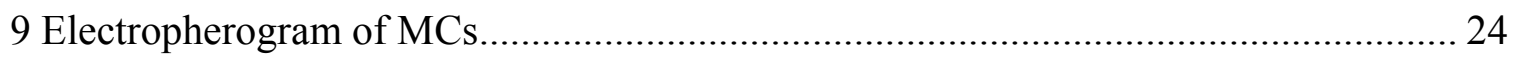

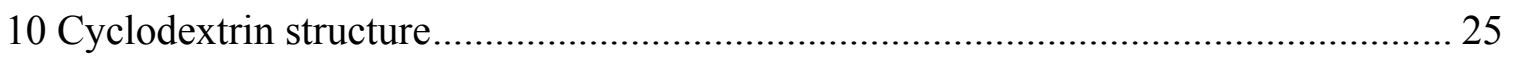

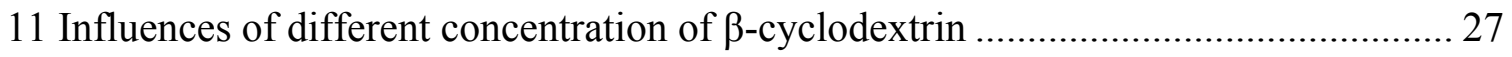

12 Electropherograms of separation of four MCs mixture ........................................ 28

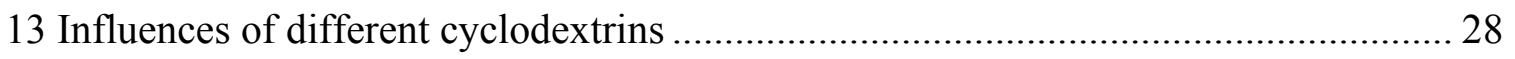

14 Influences of the migration of microcystins on the $\mathrm{pH}$ of buffer electrolyte............... 30

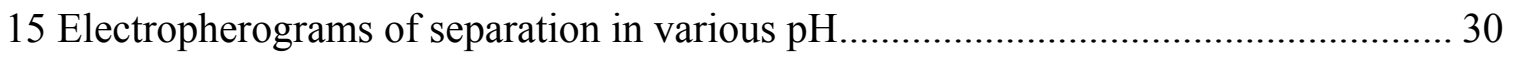

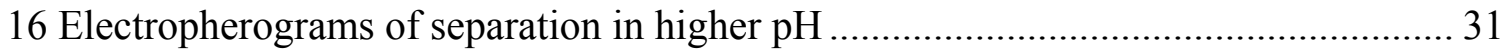

17 The change of elution order when $\beta$-cyclodextrin was added into the buffer ............ 32

18 Migration of microcystins affected by sodium phosphate concentration .................. 33

19 Linearity of CE determination of microcystins ................................................ 35

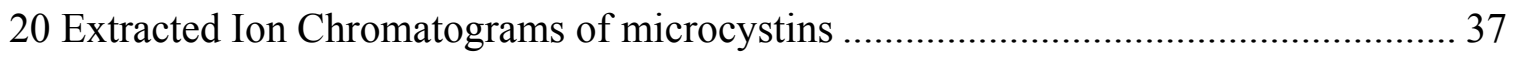

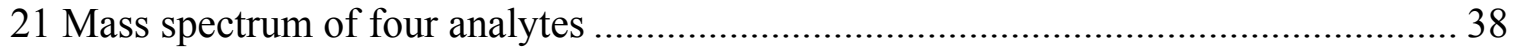


22 CE separation of real sample spiked with standards.......................................... 39

23 Mass spectrum of spiked lake water sample ......................................................... 40

24 Electropherogram of bloom sample 4 with CE method......................................... 41

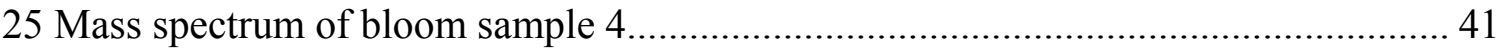

26 Electropherogram of bloom sample 8 with CE method....................................... 42

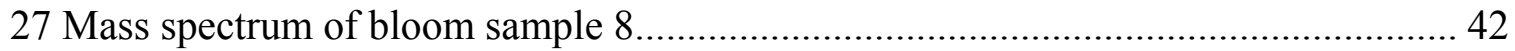




\section{CHAPTER 1}

\section{Background}

\subsection{Introduction of harmful algal blooms}

Algae are essential components of marine ecology and provide basic nutrients and oxygen for all forms of marine life. Algae are usually single-celled and autotrophic organisms, however, diverse algae are found ranging from unicellular to multicellular forms. ${ }^{1}$ Because most algae are photosynthetic and autotrophic, they grow widely on the earth. As the major component of plankton, microalgae provide basic nutrients for marine organisms, such as vitamins and polyunsaturated fatty acids. The more complex and larger forms of algae are called seaweeds, these forms are consumed by human being, and they provide iodine, potassium and a variety of other essential nutrient. ${ }^{2}$

Microalgae can grow rapidly under suitable conditions resulting in the accumulation of large populations of algae known as algal blooms. Algal blooms can occur in freshwater as well as in marine environments. ${ }^{3}$ It is easy to observe algal blooms because of the intensive green color in the water bodies. However, algal blooms may also produce brown or red coloration depending on the corresponding species of algae involved. Eukaryotic microalgae, cyanobacteria, and other harmful phytoplankton involved in algal blooms can produce dangerous toxins, resulting in events known as harmful algal blooms (HAB). ${ }^{4-6}$

Harmful algal blooms have been reported to cause worldwide environmental and human health concerns in coastal areas. In recent years, the frequency of occurrence of HAB seems to be increasing. ${ }^{7}$ Algal blooms are often caused by excess nutrients, especially phosphates, from agricultural runoff. ${ }^{4,8}$ When high concentrations of 
phosphates are introduced into aquatic systems, algae tend to grow rapidly. Cyanobacteria, also known as blue-green algae, exist in almost all aquatic environments, such as lakes, ponds, and slow-flowing streams. ${ }^{9}$ Some cyanobacteria species can even grow in soil or rocks. ${ }^{9}$ The extensive proliferation of cyanobacteria in eutrophic waters can also result in blooms. When the algae die, the cell walls of the cyanobacteria decompose resulting in the release of toxins including hepatotoxins and neurotoxins. ${ }^{10}$

\subsection{Microcystins}

Microcystins (MCs) are produced by a series of cyanobacteria, mainly including genera Microcystis, Nostoc, Planktothrix, Aphanizomenon, and Anabaena. ${ }^{4}$ The distribution of different cyanobacteria is affected by the region, in particular the water chemistry and climate. Under suitable conditions, such as warm temperatures and excess nutrients, cyanobacteria grow excessively causing blooms and releasing a variety of microcystins.

Because microcystins are hepatotoxins, efforts have been spent on the detection of MC in water sources such as sea, lake and freshwater. Microcystins are composed of seven amino acids, which can form a cyclic peptide. The general structure of MC can be represented by cyclo-(D-Ala-X-D-MeAsp-Z-Adda-D-Glu-Mdha). ${ }^{4}$ The two amino acids ( $\mathrm{X}$ and $\mathrm{Z}$ ) are variable L-amino acids and the rest five amino acids are non-proteinogenic amino acids (Fig. 1). ${ }^{11}$ The MC variants are formed by the combination of different groups in $\mathrm{X}, \mathrm{Z}, \mathrm{R}_{1}$ and $\mathrm{R}_{2}$ position. It has been reported that there are over 80 identified

variants of MC. ${ }^{12}$ The structure differences between MC molecules result in a range of polarities and hydrophobicities. 


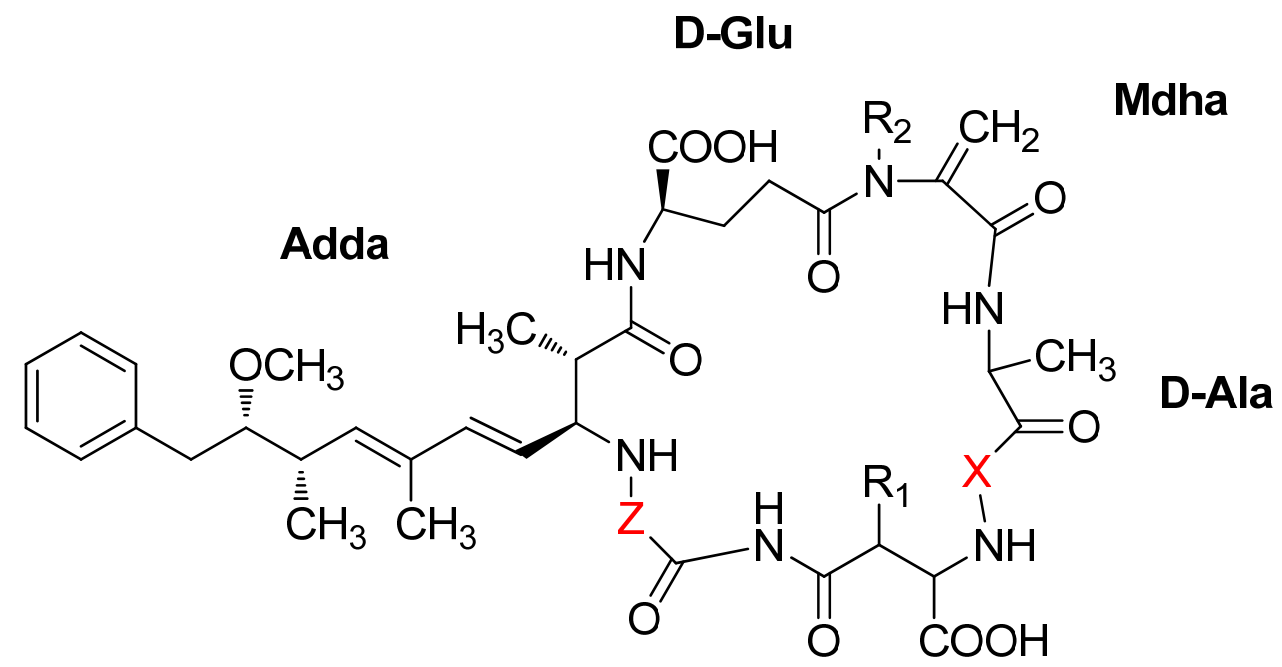

D-MeAsp

Fig. 1 General structure of microcystins. The $\mathrm{X}$ and $\mathrm{Z}$ in red indicate variable amino acids; the substituents $\mathrm{R}_{1}$ and $\mathrm{R}_{2}$ could be any functional groups.

Historically, four microcystins have been extensively studied because of their toxicity and abundance (Table 1). ${ }^{13,14}$ Both $\mathrm{R}_{1}$ and $\mathrm{R}_{2}$ in these four MCs are methyl groups but the two amino acids in the molecule vary. Microcystins are stable under natural conditions such as oxidation and hydrolysis. Studies have indicated that certain MCs can persist for years in dark and cold environments. Surprisingly, MCs can withstand high temperatures so that boiling of water cannot degrade them. Therefore, if the fresh water is contaminated by $\mathrm{MC}$, it is no longer safe for drinking and cooking. Currently the concentration limit for MC-LR or its equivalents is $1 \mu \mathrm{g} / \mathrm{L}$ on the basis of World Health Organization (WHO) drinking water guidelines. ${ }^{15}$ Moreover, consumption of MCs contaminated foods, such as agricultural products, shrimps and fishes is also dangerous. It has been noticed that MCs effects are concentration and time dependent. 
Normally, hepatotoxins can cause severe damage to human liver. Other organs such as colon and kidney can also been affected by exposure to MCs according to recent studies. Table 1. Four microcystins with their respective amino acids

\begin{tabular}{cccc}
\hline Toxins & X-position Amino & Z-position Amino & Molecular Weight \\
& Acid & Acid & \\
\hline Microcystin LR & Leucine (L) & Arginine (R) & 995.17 \\
Microcystin YR & Tyrosine (Y) & Arginine (R) & 1045.19 \\
Microcystin RR & Arginine (R) & Arginine (R) & 1038.2 \\
Microcystin LA & Leucine (L) & Alanine (A) & 910.06 \\
\hline
\end{tabular}

\subsection{Mechanisms of MC toxicity}

Microcystins are assembled by a versatile protein complex, which contains nonribosomal peptide synthetase (NRPS) and polyketide synthase (PKS) domains. ${ }^{16}$ The protein complex only exists in prokaryotes and simple eurakyotes. ${ }^{16}$ The majority of the toxins in cyanobacteria cells are localized in thylakoids, although toxins have also been found in nucleoplasm, pyrophosphate bodies and other regions. ${ }^{17}$ The accumulation of toxins in thylakoids was attributed to the interaction of the Adda amino acid and its polar cyclic structure within the thylakoids membrane and cytoplasm, respectively. It has been reported that the toxicity of MCs is affected by the Adda amino acid because oxidation and/or isomerization of Adda lowers the general toxicity of MC..$^{18,19}$

The cyclic peptides in MC tend to bind to enzymes, such as serine/threonine protein phosphatases (PPS). ${ }^{20,21}$ As a result, the activity of these enzymes is inhibited. 
Many studies have been performed on the interaction of MC with protein phosphatases PP1 (protein phosphatase 1) and PP2A (protein phosphatase 2) to elucidate the mechanism of toxicity. ${ }^{10,20,22,23}$ Protein phosphorylation and dephosphorylation, which are catalyzed by kinases and phosphatases, respectively, are an essential process in the regulation of protein activity. Inhibiting the activity of serine/threonine protein phosphatases interferes with the equilibrium of phosphorylation/dephosphorylation. The interaction of MC with PP1 and PP2A has been studied by examining the crystal structure of MC-LR bound to PP1 and PP2A. Inhibiting the activities of PP1 and PP2A is facilitated by a two-step reaction: first, MC-LR deactivates the enzyme by binding to it; next, the covalent binding of MC-LR to the enzyme forms a complex, which can persist a long time..$^{20,22}$

The mechanism of interaction between MC and PP1 has been studied in detail. The catalytic subunit of PP1, that is PP1c, can interact with MC-LR via three binding sites, the hydrophobic groove, the catalytic site and C-terminal groove. ${ }^{24}$ The activities of the two catalytic metal atoms in the phosphatase are inhibited because MC-LR facilitates the binding of two water molecules with metal atoms via the $\alpha$-carboxyl group of Dglutamic acid moiety and the adjacent carbonyl oxygen. Thus, the toxicity of the MC is highly affected by the $\alpha$-carboxyl group of the glutamic acid. In addition, the carboxyl group of the D-MeAsp in MC can interact with the Arg96 and Tyr134 residue of PP1c causing the active site of the enzyme to become inaccessible. ${ }^{25}$ The hydrophobic chain of the Adda moiety can also bind with the hydrophobic groove region of PP1c, which is close to the active site of the enzyme. The $\beta 12$ and $\beta 13$ loop can also interact with MC (Fig. 2). ${ }^{26}$ The mechanism of binding between MC-LR and PP2A was also illustrated by 
investigating its crystal structure. ${ }^{27}$ The surface pocket of PP2A, which is located above the two metal atoms and the active site of the enzyme, can bind with MC, and the binding is reinforced by the interaction between MC moieties and the residues of PP2A through hydrophobic interactions and van der Waals forces. ${ }^{27}$

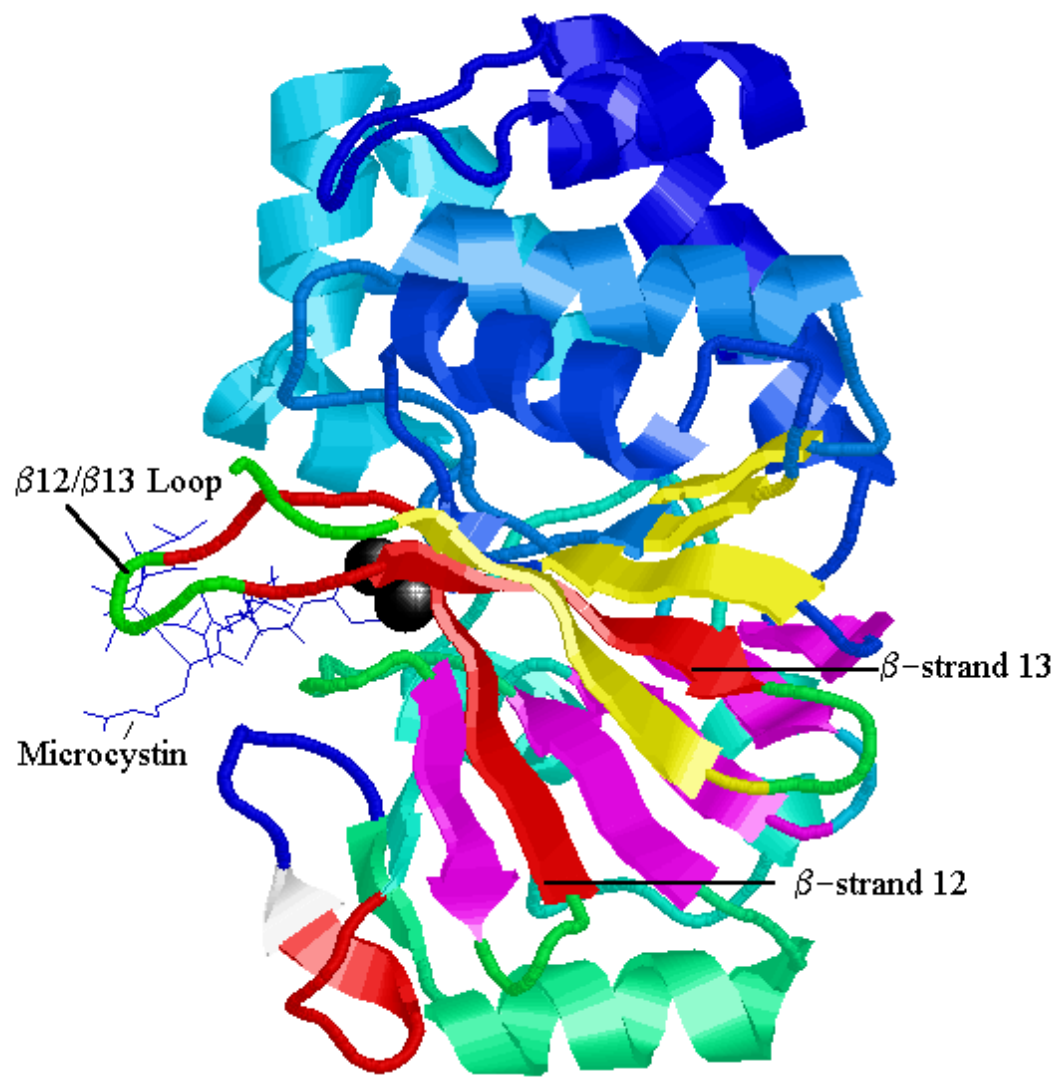

Fig. 2 Schematic diagram of microcystin binding with $\mathrm{PP} 1 .{ }^{26}$ The two metal ions are indicated in black spheres.

\subsection{Determination of MC with high performance liquid chromatography}

Microcystins are composed of small peptides. Historically, determination of microcystins (MC) was performed using reverse phase high performance liquid chromatography (RP-HPLC). ${ }^{28-31}$ Especially, HPLC coupled with mass spectrometry (MS) has been particularly useful in determining the structure of new MC toxins. ${ }^{31} \mathrm{~A}$ 
number of different HPLC columns, including $\mathrm{C} 18$, anion-exchange, and monolithic columns have been utilized as stationary phases for the separation of microcystins. ${ }^{32-34}$ The mobile phases used in HPLC analysis include water, methanol and acetonitrile $(\mathrm{ACN})$.

In general, $\mathrm{C} 18$ columns are widely used for MC analysis because they have high resolution and are commercially available. The resolution of the C18 columns is controlled by the diameter of the beads used in these columns. Generally, the particles used for $\mathrm{C} 18$ columns are less than $5 \mu \mathrm{m}$ and the column bore is less than $2 \mathrm{~mm} .^{35-41}$ Anion-exchange columns have been reported to have better resolution than $\mathrm{C} 18$ for the analysis of LR and YR when the columns were modified with functional groups, such as diethylaminoethylene. ${ }^{29}$ Monolithic columns have been used to decrease the analysis time for the detection of MC because of the high flow rate that can be used with such columns. ${ }^{42,43}$ However, the detection limit was found to be poor when using these types of stationary phases because of high baseline noise. High flow rates were also seen to produce a lack of homogeneity in the mixed mobile phase gradient, further increasing the noise.

The elution methods for HPLC analysis of MCs include both isocratic and gradient methods using methanol or acetonitrile as the organic co-solvent. Trifluoroacetic acid (TFA) and formic acid are generally used to adjust the $\mathrm{pH}$ of the mobile phase and affect the elution as counter ions. Several other modifiers of the HPLC solvents have also been used, including ammonium acetate, phosphate, and nano-fluoropentanoic acid. ${ }^{44}$ The detection of target MCs was commonly facilitated by monitoring with a photodiode array detector at a wavelength of $238 \mathrm{~nm}$. Identification of specific MCs via HPLC can 
be performed when mass spectrometry is employed during analysis. Tandem mass spectrometry (MS/MS) can identify unknown MCs more accurately and efficiently.

\subsection{Determination of microcystins using capillary electrophoresis}

\subsubsection{Introduction of capillary electrophoresis}

Electrophoresis is the directional movement of the charged species in an electrolyte under the influence of a spatially uniform electrical field. ${ }^{45-47}$ Depending on the type of analyte and users preference, electrophoresis can be performed using a variety of different media including free buffer, gels and capillaries. Electrophoresis performed in a free buffer solution is limited by convection and thermal diffusion. Gel electrophoresis requires a gel (agarose or polyacrylamide gel) to provide a porous medium, and can be performed in slabs, tubes and gel trays containing conductive fluid. Although gel electrophoresis has been extensively used for separating macromolecules, nucleic acids and proteins, improvements in separation efficiencies, automation, detection, and analysis time, are still needed.

Capillary electrophoresis (CE) employs a small capillary tube to contain an electrophoresis buffer medium. A voltage is then applied across the capillary to mobilize the analytes and facilitate their separation on the basis of differential migration rate in the applied electrical field. ${ }^{45}$ The capillary tubes are usually $25-100 \mathrm{~cm}$ long and have a narrow bore $(25-75 \mu \mathrm{m}$ inner diameter). The physical properties of capillary tube enhance its application in electrophoresis because of its high electrical resistance, anti-convective properties and efficient heat dissipation. ${ }^{45}$ The electrical resistance of the capillary tube permits the application of high electrical fields while generating only minimal heat during electrophoresis. The large surface area to volume ratio of the capillary tube further 
improves the heat dissipation. As a result, $\mathrm{CE}$ analysis under high electrical field can be completed in a short time with high resolution. Historically, CE has been applied in numerous research and industrial areas, including the separation of amino acids, proteins, chiral molecules, drugs and toxins. Analysis by $\mathrm{CE}$ is environmental friendly because it requires only a minimal amount of sample and generates less liquid waste than other chromatographic methods.

\subsubsection{Principles of CE}

Separation by CE depends on the difference in velocity of charged species in an electrical field. ${ }^{46,48}$ The velocity of a particle is determined by the following equation:

$$
\begin{gathered}
v=u_{e} E \\
u_{e}=\frac{q}{6 \pi \eta r}
\end{gathered}
$$

Where: $v=$ particle velocity, $u_{e}=$ electrophoretic mobility, $E=$ applied electric field, $q=$ particle charge, $\eta=$ viscosity of the solvent, $r=$ hydrodynamic radius of the particle.

Because the applied electric field is a constant, the velocity of the particle is affected by its electrophoretic mobility. Therefore, the velocity of the particle is only affected by its charge and hydrodynamic radius. Small and highly charged particles move faster than large and minimally charged species. Several factors including temperature, buffer $\mathrm{pH}$ and composition, and wall coatings of the capillary tube also affect the $\mathrm{CE}$ separation.

Traditionally, capillary tubes used during CE analysis are made of fused silica.

Under aqueous conditions, the inner wall of the capillary tube can possesses charge. ${ }^{48}$ 
The appearance of excess charge on the interior surface is attributed to the ionization of the inner surface and/or adsorption of ionic species. In particular, the formation of the anion $\left(\mathrm{SiO}^{-}\right)$becomes significant when the buffer $\mathrm{pH}$ is above 4 . As a result, cations from buffer are attracted to the anionic surface leading to the formation of a diffuse double layer (Fig. 3). When the capillary is exposed under an electrical filed, the cations distributed on the inner surface of the capillary will move towards the cathode. Because the cations are dissolved in the solution, their movement drives the bulk solution flow along the same direction. The motion of the bulk liquid inside of the capillary is induced by the movement of the accumulated cations layer under an applied electrical filed, and this phenomenon is known as electroosmotic flow or electroendosmotic (EOF). The EOF is greatly affected by the $\mathrm{pH}$ of the buffer solution inside of the capillary because EOF depends on the ionization of the silanol groups. At higher $\mathrm{pH}$, the majority of the silanol groups are deprotonated and thus the EOF becomes significant. Changing the coating of capillary inner surface, electric field and buffer composition also has a large effect on EOF. ${ }^{48}$ The EOF usually is controlled to obtain an efficient separation.

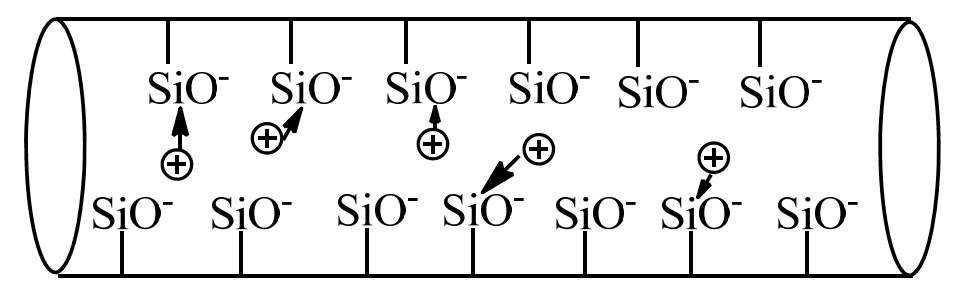

(b)

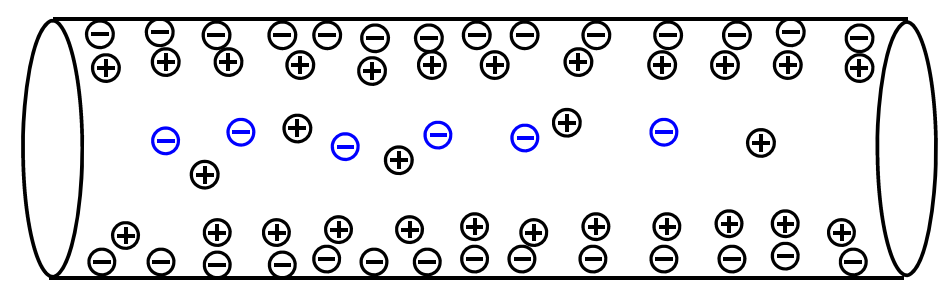


(c)

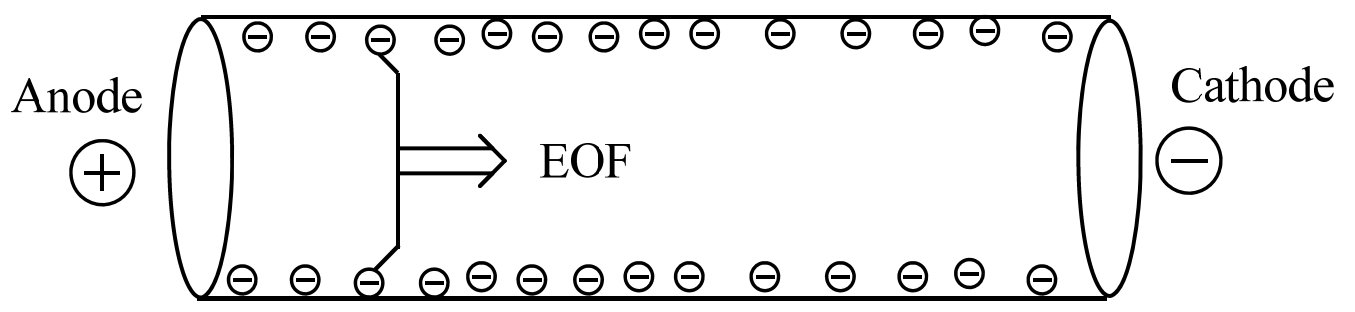

Fig. 3 Formation of EOF inside of the capillary tube: (a) ionization of the capillary inner surface; (b) formation of a diffuse double layer; (c) formation of EOF inside of the capillary under an applied electrical filed.

\subsubsection{Advantages of CE detection}

When the UV-Vis spectrophotometer is utilized as the detector of CE instrument, a part of the capillary tube is utilized as the optical detection cell. This on-tube detection enhances CE resolution compared with other UV-Vis detections. However, the width of capillary is narrow resulting in weak sensitivity. Therefore, capillaries are coated with a polymer layer to increase their flexibility so that the section of capillary used as UV-Vis detector can be modified to improve path length of the detection cell. Usually, the detection section of the capillary can be made into a "bubble" or a "Z" shape. A long path length proves a higher sensitivity during $\mathrm{CE}$ analysis.

Because the driven force of the EOF is evenly distributed along the capillary wall, the driven force on the bulk solution is uniform and the bulk solution moves at a constant rate. The shear force and friction caused by capillary wall only slow down a very thin layer along the capillary wall and are negligible as for the overall separation process. Therefore, a flat flow velocity profile is obtained during the EOF (Fig. 4). ${ }^{45,46,48}$ Normally, the flat flow profile is independent of the internal diameter of the capillary. The 
advantage of the flat flow profile is that the solute zones become sharp when compared with separation under a parabolic flow profile such as is seen with HPLC methods. As a result, the flow velocity profile can affect the peak shape and efficiency of chromatography by minimizing diffusion.

Laminar flow

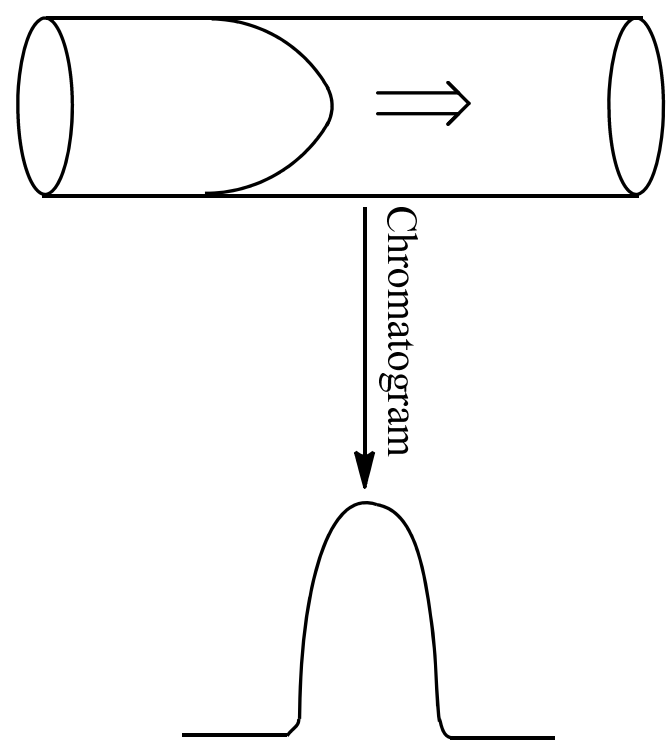

EOF

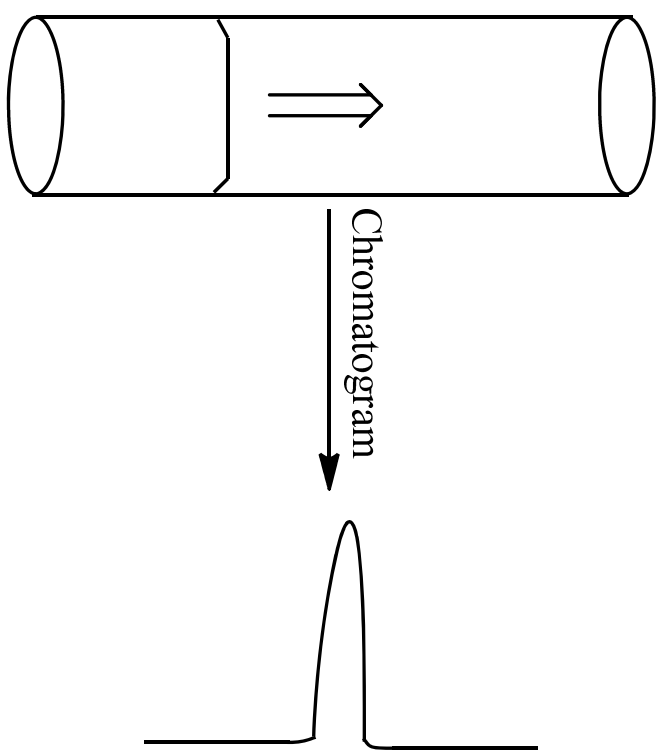

Fig. 4 Flow velocity profiles and their resulting chromatograms

Another advantage of CE separation is that almost all species, such as cations, neutral molecules, and anions can be eluted in the same direction because of EOF (Fig. 5). Under the electrical field, the flow of target species is determined by both EOF and electrophoretic attraction. Normally, when the capillary inner wall is negatively charged, the direction of EOF is towards the cathode. All the cations and neutral species have the same flow direction as EOF. Anions may also flow in the same direction of EOF if the magnitude of EOF is larger than the electrostatic force. Under such conditions, all species 
are carried towards the cathode following a specific order: cations, neutral ions, and anions. Hence, the uncharged molecules and anions can also been eluted and analyzed.

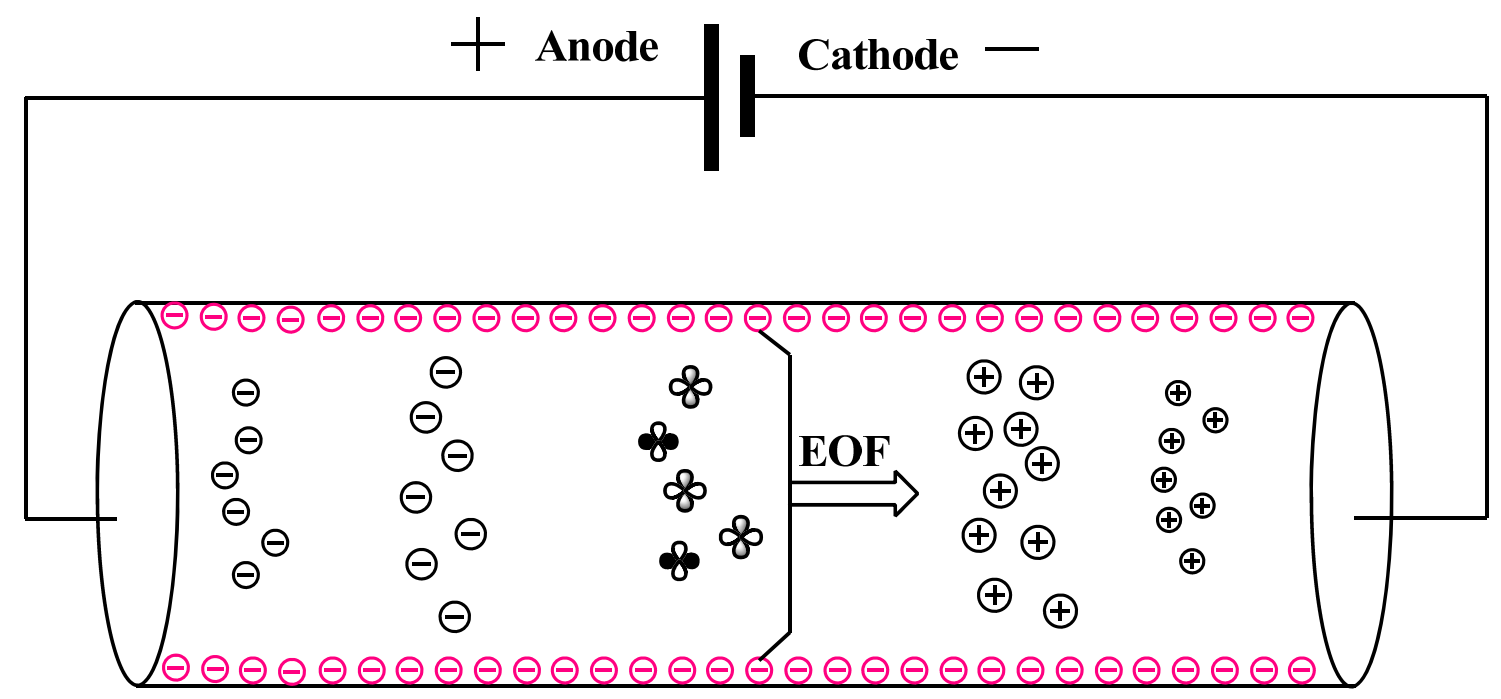

Fig. 5 Elution of ions and neutral molecules under EOF

\subsubsection{Instruments for CE separation}

The commonly instrument used for CE separation can be illustrated in Fig. 6. Generally, the CE instrument is composed of sample vial, inlet and outlet reservoir, capillary, electrodes, high voltage power supply, detector and computer control. The capillary, inlet and outlet reservoir contain an electrolyte. At a sufficiently high EOF, all ions will migrate towards cathode when using a bare fused silica capillary. It is also common for a detection window to be etched into the wall of the cathode end of the capillary to permit analysis by UV detector. A dual polarity (DC) power supply is utilized in case that the power supply needs to switch polarity because of the reversed EOF. The applied voltages range from 0 to $30 \mathrm{kV}$. To improve analysis efficiency, multiple capillaries can be employed to facilitate the separation simultaneously, which is known as 
capillary array electrophoresis (CAE). Typically, CAE is utilized for DNA sequencing and the instruments are more complex in terms of sample introduction and detection.

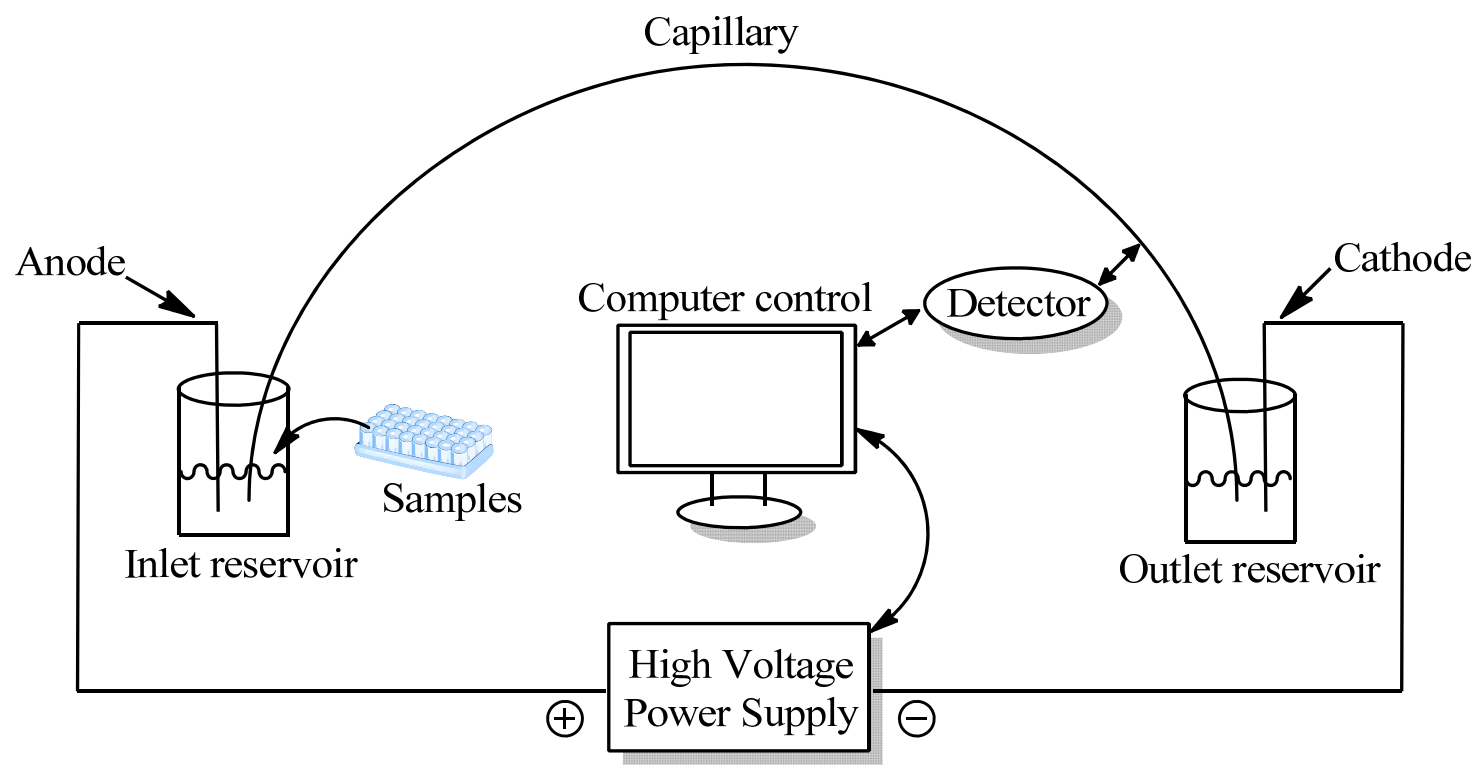

Fig. 6 Schematic illustration of CE instruments

The sample volume required for $\mathrm{CE}$ separation is small and limited by the capacity of the capillary tube. The sample can be introduced into the capillary tube by hydrodynamic injection or electrokinetic injection (Fig. 7). After injection, the capillary tube is returned to the inlet reservoir. Hydrodynamic injection, which is the most commonly used method, requires a difference between inlet and outlet in either pressure or height. ${ }^{48}$ The pressure difference can be achieved by applying pressure at the sample inlet or a vacuum at the outlet of the capillary. The difference in height utilizes the gravity force to facilitate siphoning between the two sides of capillary. The height of sample vial is raised up for a short while to facilitate the sample introduction. The injection volume using hydrodynamic injection can be controlled by changing pressure and injection time. 


\section{Hydrodynamic}

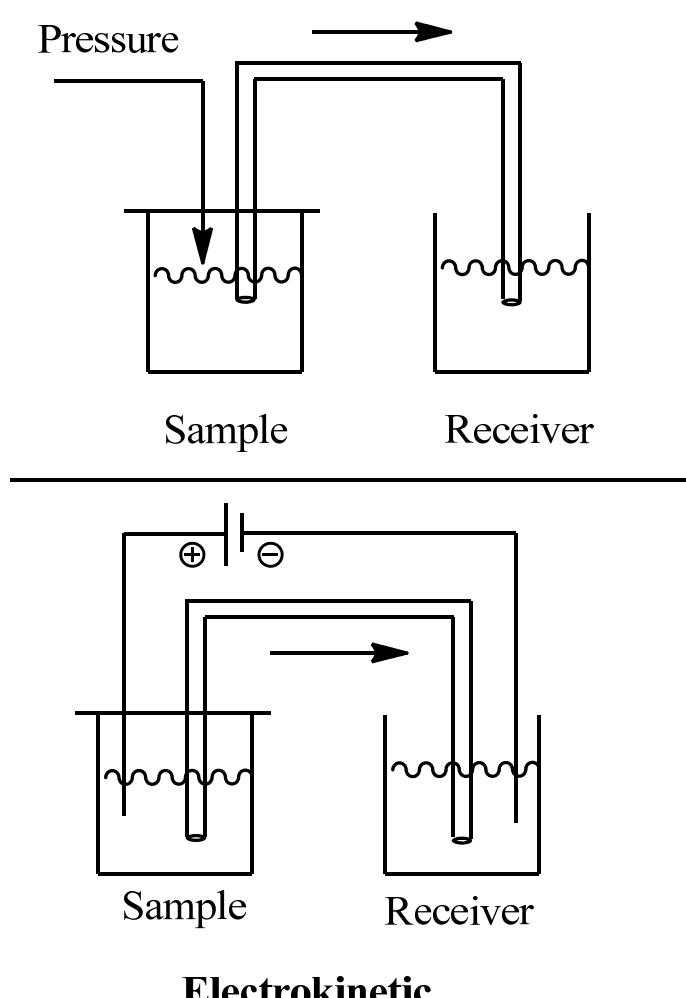

\section{Electrokinetic}

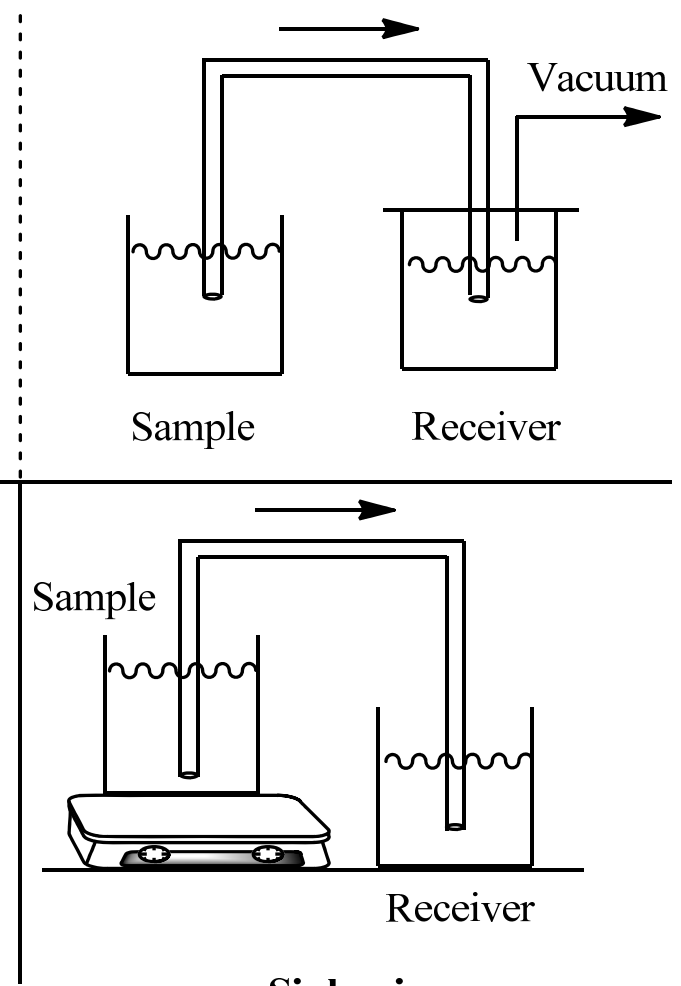

Siphoning

Fig. 7 Sample injection methods for CE

Application of a high voltage on the two sides of capillary for sample injection is known as electrokinetic injection. ${ }^{49}$ The analytes are introduced into capillary by the electrophoretic migration and EOF forces. The quantity of the injected analyte is dependent on the electrophoretic mobility of each analyte, which does not occur on hydrodynamic injection. Electrophoretic injection is preferred when the capillary contains gels or stationary phases. The presence of gel may cause high back pressure, which makes the hydrodynamic injection inefficient.

Detection in CE separation is vital to monitor the separation process and maintain the sensitivity. Historically, many detection methods have been extensively used during CE separation, such as UV-Vis spectroscopy, fluorescence, and mass spectrometry. 
Ultraviolet-visible spectroscopy is most commonly used methods in CE separation because it has been well developed for liquid chromatography and can be easily incorporated into the CE instrument. The UV-Vis detector can monitor the absorption of the analyte between $200 \mathrm{~nm}$ and $700 \mathrm{~nm}$. Normally, UV-Vis detection is performed oncolumn through a window etched into the capillary wall. This is an advantage over HPLC methods as there is no dead-volume between the separation and the detection.

\subsection{Fundamentals of CE-MS}

Mass spectrometry (MS), which is widely used as a detector for liquid chromatography, has also been used extensively as a detector in CE separation. Unlike UV-Vis detectors, MS has the ability to separate and identify molecular species on the basis of their mass-to-charge ratio. Coupling of CE and MS not only improves selectivity but also can assist in the determination of the structure of the analyte. During $\mathrm{CE}$ separation, all analytes are separated in a buffer solution and are eluted in the liquid form. Therefore, solutes separated after CE must be volatilized before being transferred into the mass spectrometer. Electrospray ionization (ESI) is the most commonly used ionization source in CE-MS. Analytes separated following CE are ionized and volatilized by ESI and the resulting gaseous ions are further separated by an analyzer, such as quadrupole, time-of-flight (TOF) and ion trap based mass analyzer.

Electrospray ionization (ESI) has been developed and extensively used in liquid chromatography. Application of ESI as an ionization source in CE-MS is advantageous because of the fact that this is a concentration sensitive detector. Solvent containing analytes exiting from separation capillary are dispersed into very small droplets by electrospray. The volatile solvents including mixture of water and methanol are 
evaporated, which is known as desolvation. During desolvation, the size of the droplets is further decreased by losing the neutral solvent molecules. The aerosol is then pumped into another chamber by vacuum via a capillary tube, which is heated to facilitate further evaporation of the solvent. Because the neutral solvent molecule evaporates from the charged droplet, the surface charge of the droplet increases extensively. The electrostatic repulsion of the charged droplet becomes much higher than its surface tension resulting in an explosion, which is known as coulomb fission. The charged droplets become even smaller and more stable after the coulomb fission cycles. Consequently, only charged solutes remain to be emitted into mass spectrometer.

Application of ESI as an ionization source requires a high electrical field between the exit of the separation capillary and the entrance of mass spectrometer. Therefore, several interfaces have been developed to maintain the work efficiency of CE-MS, including electrical interfaces, sheath flow interfaces and sheathless interfaces. In electrical interfaces, the tip of the separation capillary is at ground and a high voltage used for ESI is applied to the mass spectrometer. When the potential of the MS entrance capillary is negative, the positive ions in the analyte will enter the MS, and vice versa. When the capillary end is placed in the high voltage electrical field, the electrical current caused by $\mathrm{CE}$ background electrolyte conflicts with the current driven by the electrospray potential. Therefore, a resistor sink is used as a ground path for the electrical current.

The most commonly used interface in CE-MS is the sheath flow interface, which utilizes a tri-axial capillary sprayer containing three different components (Fig. 8). ${ }^{50}$ The outlet of the CE separation capillary is located in the center of a tri-axial sheath flow sprayer as a spray tip. The sheath solvent, which flows along the outside of the capillary, 
contacts with CE background electrolyte directly. The application of sheath solvent can enhance hydraulic flow and facilitate the electrospray even without EOF. In addition, the sheath flow has been demonstrated to promote ionization of analyte. As a result, the formation of cations and anions is less dependent on the $\mathrm{pH}$ of the background electrolyte. The sheath solvent used in this research was $50 \% \mathrm{vol} / \mathrm{vol}$ methanol in water. Other aqueous mixtures, such as acetonitrile, isopropanol have also been used as a sheath solvent. Typically, the flow rate of the sheath solvent is between 1 and $10 \mu \mathrm{L} / \mathrm{min}$. The outer tube supplies a nebulizing gas, such as nitrogen, to assist the spray.

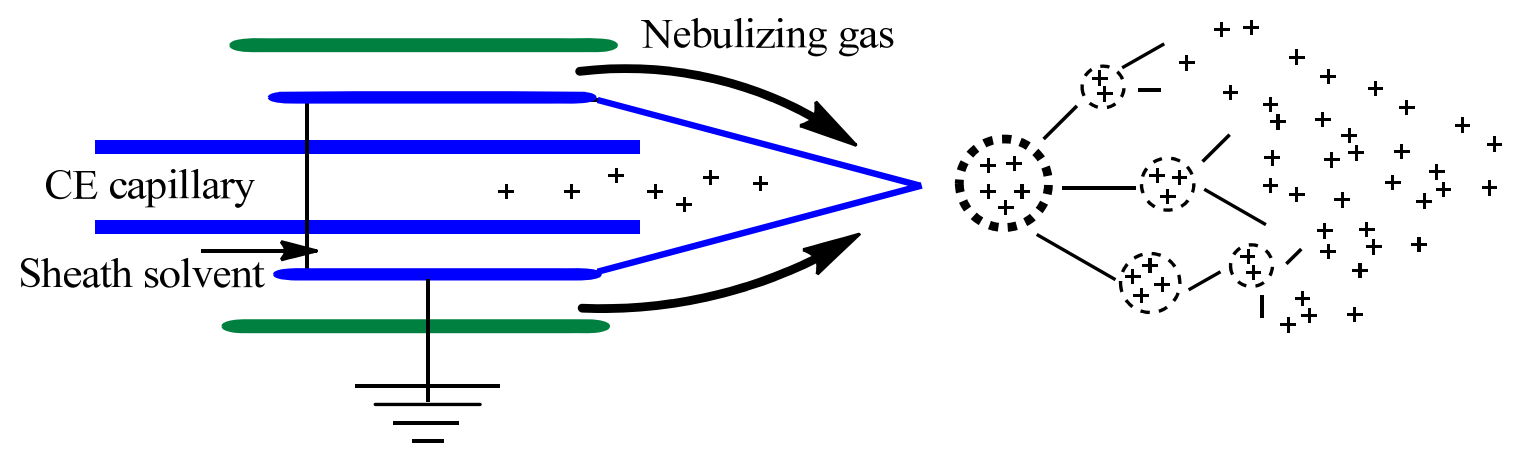

Fig. 8 Tri-axial capillary sprayer used in sheath flow interface.

\subsection{Applications of CE-MS}

After the introduction of CE-MS by Olivares et al. in 1987, CE-MS has been applied in many aspects, such as environment, bioanalytics, forensics, pharmaceutics and metabolites, because of its selectivity and efficiency ${ }^{51,52}$ Many researches using CE-MS have been performed on the separation of biological molecules including proteins, peptides and nucleic acids. ${ }^{53-55}$ For example, CE-MS has been reported to be utilized in the analysis of polypeptide patterns in human body fluids. ${ }^{56}$ Analysis using CE-MS can rapidly diagnose specimen with high sensitivity and reproducibility. For example, the determination of the protein concentration in urine excreted by patients with renal 
diseases can help to understand the state of an illness. Usually, the urine samples are loaded onto a column and eluted with organic solvent to remove urea, electrolytes, salts, and other interferences. The resulting samples are then reconstituted in water before analysis to increase polypeptide concentration.

\subsection{Microchip Capillary Electrophoresis}

Generally, a real-time, continuous, portable, and simple analysis method is needed for field application. Capillary electrophoresis is perfect for microchip technology because of some inheritance advantages of CE method, such as low injection volume and fast, efficient separations. Recent innovations in this field have achieved the integration of sample collection, sample preparation, and sample analysis onto a single platform most commonly referred to as a Lab-on-a-Chip (LOC) or micro Total Analysis System ( $\mu$ TAS). This application has the potential to provide inexpensive detection device for portable, clinical or deployable analysis. ${ }^{57}$ The chip patterning technique has been well developed to allow mass production of LOC devices. The LOC method also allows multi-analyte

analysis to take place simultaneously. ${ }^{58}$ Moreover, LOC will lead to the development of portable devices for environmental monitoring. Some successful attempts have been made in this field seems to be promising. The developed CE and CE-MS methods will ultimately be integrated into a $\mu$ TAS by collaborators for real-time, continuous detection of cyanotoxins, specifically the microcystin family. 


\section{CHAPTER 2}

\section{Materials and Methods}

Capillary electrophoresis is a separation technique that has different modes and different detection methods for separation and determination of compounds with different chemistries. A CE system with UV detection was initially used to develop a separation then this procedure was modified to permit MS detection. In the first stage of method development, CE was studied and developed for separation of four microcystins: LR, YR, RR, and LA. These four microcystins are the frequently found variants occurring in the environment. ${ }^{12,13}$ The details of method development utilizing CE-UV and CE-MS are shown in the following sections.

\subsection{Chemicals and samples}

All chemicals used in this research were of analytical grade. Sodium phosphate monobasic monohydrate for electrophoresis (Sigma, MO, USA) and sodium phosphate diabasic heptahydrate (Acros, New Jersey, USA) were used for preparing buffer electrolytes. $\beta$ - and $\gamma$-cyclodextrin were purchased from TIC America (Tokyo, Japan). HPLC-grade 2-proponal, acetonitrile, methanol and dimethyl sulfoxide were supplied by Fisher Scientific (New Jersey, USA). Dimethyl sulfoxide was used as internal standard to determine EOF. HyperSep C18 solid phase extraction cartridges were from Thermo Fisher Scientific (Pennsylvania, USA). Microcystins YR, LR, and LA were obtained from Carmichael. Microcystin RR and lake water samples were from Beagle Bioproducts (Ohio, USA). The general structure of microcystins is shown in Fig. 1. 


\subsection{Sample Preparation}

Standard microcystin solutions of $200-1000 \mu \mathrm{g} / \mathrm{mL}$ were prepared by dissolving 0.1-0.5 mg of each individual standard microcystin in $0.5 \mathrm{~mL}$ methanol. For the samples to be tested, known amount of standard solution was spiked in either nanopure water or lake water. Extractions of samples were performed on HyperSep C18 SPE cartridge aided by an SPE manifold.

\subsection{Extraction of microcystins}

The extraction and clean-up of microcystins was performed according to previous reports. $^{59}$ The algae samples were first filtered through $0.45 \mu \mathrm{m}$ glass fiber filters (Whatman GF/C, $47 \mathrm{~mm}$ diameter). The filtrates were extracted twice in water/methanol (50:50; v:v), followed by sonication for 20 minutes and centrifugation. The supernatant was filtered with $0.45 \mu \mathrm{m}$ pore size nylon filter.

Solid phase extraction was next used to remove any impurities and to concentrate the analytes due to the short optical path length of UV detection method. The C18 SPE cartridge was conditioned with $5 \mathrm{~mL}$ of methanol and $5 \mathrm{~mL}$ of water containing $0.05 \%$ trifluoroacetic acid (TFA) for 5 minutes. The algae extracts was then transferred to the cartridge. $5 \mathrm{~mL}$ water containing $0.05 \%$ TFA was used to rinse the cartridge for the first time, and the second rinse was carried out using $5 \mathrm{~mL}$ water containing $0.05 \%$ TFA/methanol (60:40, v:v). Microcystins were eluted with $2 \mathrm{~mL}$ methanol. The eluted fraction was carefully evaporated to dryness under nitrogen. The residue was re-dissolved with $200 \mu \mathrm{m}$ water/methanol (50:50, v:v). 


\subsection{CE instruments and separation conditions}

Capillary electrophoresis was performed on an Agilent G1600 system (California, USA) equipped with diode array detection (DAD) system. The detection wavelength was set at $240 \mathrm{~nm}$ for microcystins. Separation was performed using fused silica capillaries of $50 \mathrm{~cm}$ x $50 \mathrm{~mm}$ ID (Polymicro Technologies, AZ, USA). The total length of capillaries was $50.0 \mathrm{~cm}$ and $44.5 \mathrm{~cm}$ to detector. The capillaries were preconditioned by flushing 15 minutes of $0.1 \mathrm{M} \mathrm{NaOH}$, followed by 15 minutes of deionized water and 15 minutes of buffer electrolyte. After daily use, the capillaries were flushed with $0.1 \mathrm{M} \mathrm{NaOH}$ for 5 minutes, deionized water for 5 minutes, and buffer electrolyte for 5 minutes to remove any component that may attach to the capillary walls. In between runs, the capillaries were flushed with $0.1 \mathrm{M} \mathrm{NaOH}$ for 1 minute, deionized water for 1 minute, and buffer electrolyte for 1 minute in order to improve repeatability. Hydrodynamic sample introduction method was used for injecting samples by pressure at $50 \mathrm{mbar}$ for $10 \mathrm{~s}$. The voltage applied was $+20 \mathrm{KV}$ at cassette temperature of $25^{\circ} \mathrm{C}$. The electropherograms were acquired and analyzed using ChemStation software Version 7.01 (Agilent instruments, California, USA).

\subsection{Buffer Electrolyte}

Sodium phosphate was investigated as possible buffer electrolyte. The concentration of buffer varying from 10 to $100 \mathrm{mM}$ at various $\mathrm{pHs}$ from 2.0 to 10.0 .

\subsection{Mass spectrometry}

The samples were identified by CE coupled to time of flight (TOF) mass spectrometry (Agilent, CA, USA) using a positive ESI source. Methanol/water was used as the sheath liquid $(50: 50, \mathrm{v} / \mathrm{v})$ with a flow rate of $3 \mu \mathrm{L} / \mathrm{min}$ delivered by a Jasco pump 
(Jasco, Tokyo, Japan). The nebulizer gas was maintained at $10 \mathrm{psi}$ and drying gas kept at $250{ }^{\circ} \mathrm{C}$ at a flow rate of $5.0 \mathrm{~L} / \mathrm{min}$. The voltage in producing the ion spray was $3000 \mathrm{~V}$ for the capillary. Voltage at fragmentor, skimmer, and octople were $125 \mathrm{~V}, 40 \mathrm{~V}$ and $300 \mathrm{~V}$, respectively. The reference mass was 121.0509 and 922.0098. The capillary was positioned about $5 \mathrm{~mm}$ out of the spray needle. 


\section{CHAPTER 3}

\section{Results and discussion}

\subsection{Optimization of separation conditions}

In CZE analysis, the separation of analytes depends on the differential migration of electric charge to molecular size in an electric field. The studied MCs can be either anionic or cationic depending on the $\mathrm{pH}$ of the background electrolyte. In preliminary experiments, a buffer composed of $50 \mathrm{mM}$ sodium phosphate at a $\mathrm{pH}$ of 8.0 was used. These conditions were used as starting point for further method optimization.

Three microcystin variants were tested under the initial conditions, and two peaks appeared in the electropherogram (Fig 9). The co-eluting species were MC-YR and MCLR. The separation took less than 6 minutes to complete. This result was reproducible. In order to resolve MC-YR and MC-LR, it was determined that buffer chemistry, the effect of mobility modifiers such as cyclodextrins, and the effect of $\mathrm{pH}$ needed to be evaluated.

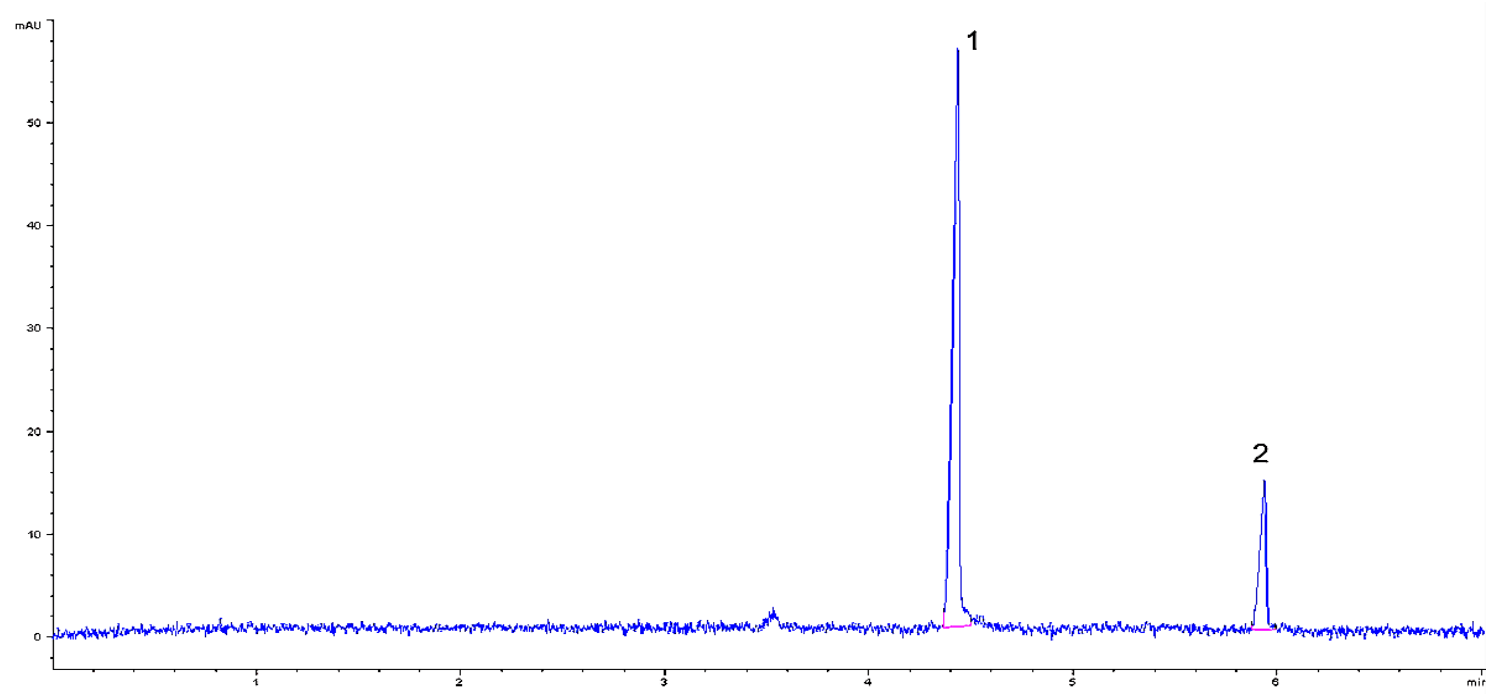

Fig. 9 Electropherogram of MCs: (1) MC-YR (25 $\mu \mathrm{g} / \mathrm{mL})$ and MC-LR (50 $\mu \mathrm{g} / \mathrm{mL})$; (2) MC-LA $(25 \mu \mathrm{g} / \mathrm{mL})$. Buffer: $50 \mathrm{mM}$ sodium phosphate, $\mathrm{pH} 8.0 . \lambda=240 \mathrm{~nm}$, voltage $=$ $25 \mathrm{KV}$. 


\subsubsection{Selection of cyclodextrin as additive in buffer electrolyte}

In general, separation by $\mathrm{CE}$ is achieved by the differences in charge-to-size ratio of analytes in an electric field. The addition of ionic surfactants to background electrolytes has been reported to improve separation in $\mathrm{CE}$, especially in chiral separations. ${ }^{60}$ When chiral selectors are added into the buffer electrolyte, analytes would complex with chiral selectors, and the enantiomers are separated based on the changes of mobility.

Cyclodextrins (CD) and their derivatives have been used to improve selectivity in a variety of applications. ${ }^{61}$ The addition of CDs has become an attractive approach in many different areas including pharmaceutical and environmental researches. ${ }^{62,63} \mathrm{CDs}$ molecules are composed of repetitive D-glucopyranose as illustrated in Fig. 10 Primary hydroxyl groups define the narrow opening of the $\mathrm{CD}$ molecule, while secondary hydroxyl groups define the wider opening. The interiors of $\mathrm{CD}$ molecule are composed with oxygen or methane groups. Thus CDs have a hollow inner cone with a hydrophobic cavity and a hydrophilic interior. CDs exhibit complexation with numerous numbers of compounds and been widely used in chiral separation in CE. The principle for chiral selection by CDs involves the formation of a guest-host complex as shown in Fig. 10 When a neutral or charged analyte complexes with the $\mathrm{CD}$, the amount of time spent in the complexes varies, and thus the average charge to size ratio of the compound changes, effecting the overall electrophoretic mobility. This mode of CE analysis can be potentially useful in the separation of MCs if differences in molecular structure result in changes in mobility upon comlexing with $\mathrm{CD}$. Thus the effect of different CDs on the separation was examined. 
(A)

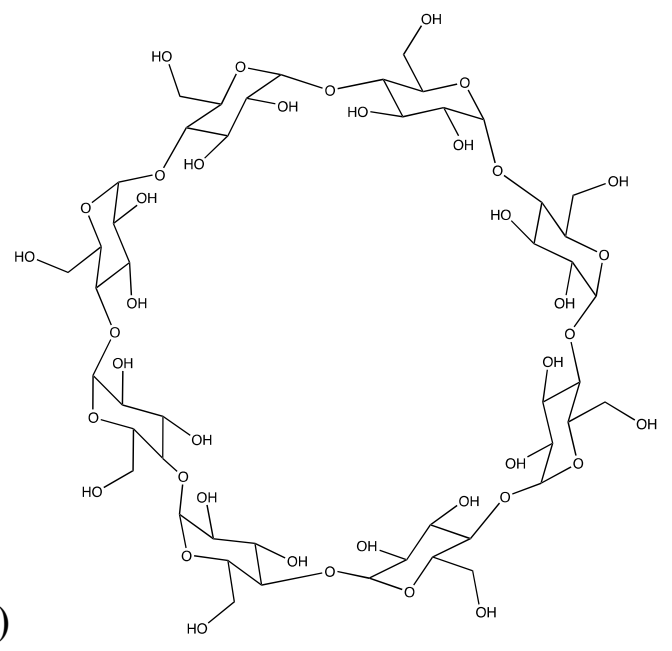

(B)

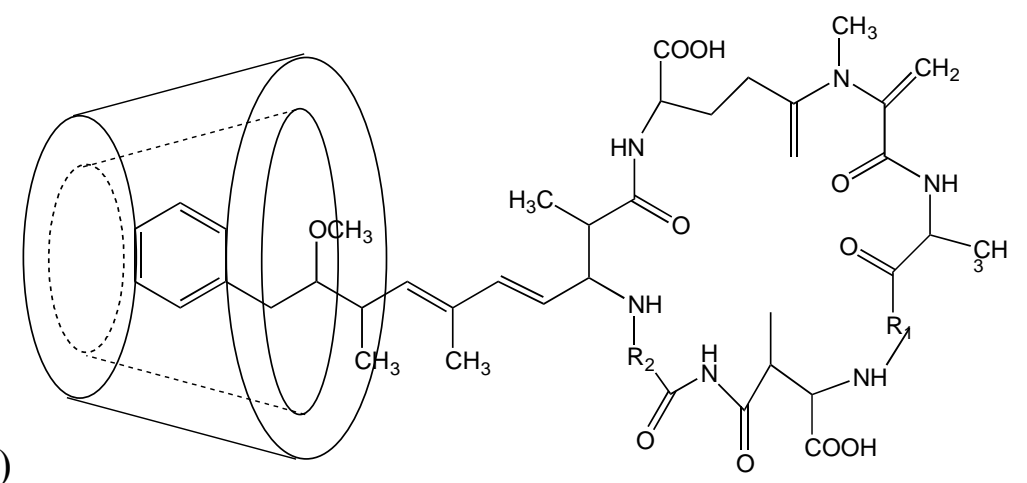

Fig. 10 Cyclodextrin structure: (A). Molecular structure of $\beta$-cyclodextrin. (B). Conical representation showing hydrophilic exterior and hydrophobic cavity.

The first step in method development was to select appropriate CD reagents. In this research, $\alpha-, \beta-, \gamma-$, sulfated $\beta$-, and highly sulfated $\gamma$-CD were studied. Among the cyclodextrins mentioned above, the results were most improved with the addition of $\beta$ CD. However baseline separation was not achieved. To further improve the separation, the effect of different concentrations of $\beta-\mathrm{CD}$ in sodium phosphate buffer was studied. It was expected that the hydrophobic cavity of $\beta-C D$ would complex with the Adda chain of microcystins. ${ }^{64}$ As the $\beta-C D$ concentration was increased, the migration time became longer. A higher $\beta$-CD concentration was beneficial for complex formation, resulting in a 
slower migration of the analytes in the background electrolyte because of an increase in average size of the analyte. At higher concentrations of CD, the separation time increased without an improvement in resolution. The optimized CD concentration was determined to be $20 \mathrm{mM}$.

In further experiments, MC-RR was also added to the mixture and the resultant separation is showing in Fig. 11. Under basic condition, all MCs were negatively charged and migrated after the EOF. MC-RR had two negative charges from arginine and migrated towards the cathode faster. Both MC-LR and MC-YR had a single negative charge. Leucine is more hydrophobic than tyrosine; therefore MC-YR migrated faster than MC-LR. MC-LA has two hydrophobic amino acids leucine and alanine, and thus migrated the slowest.

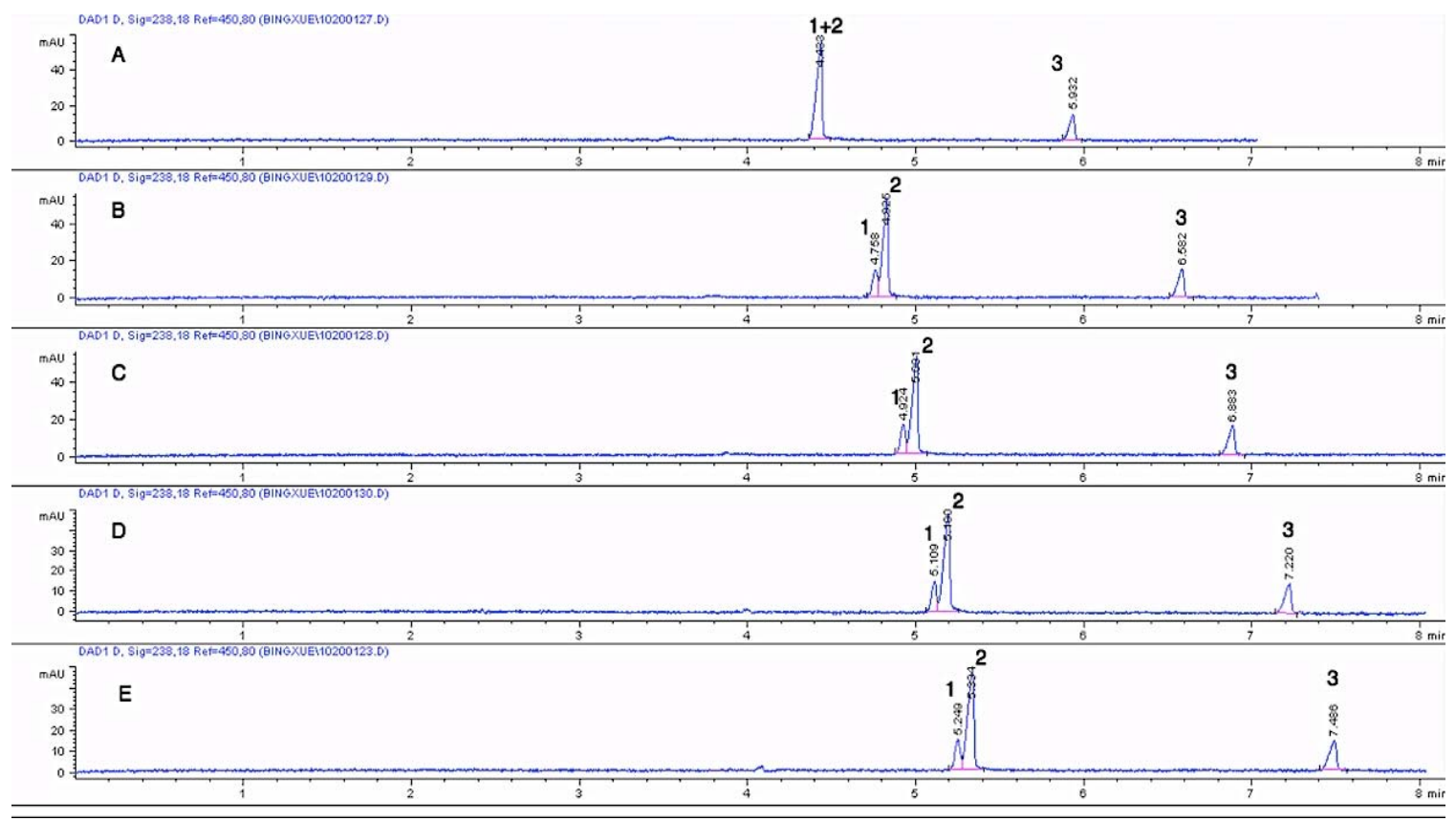

Fig. 11 Influences of different concentration of $\beta$-cyclodextrin: A. $0 \mathrm{mM} \beta$-cyclodextrin; B. $5 \mathrm{mM} \beta$-cyclodextrin; C. $10 \mathrm{mM} \beta$-cyclodextrin; D $15 \mathrm{mM} \beta$-cyclodextrin; E. $20 \mathrm{mM}$ $\beta$-cyclodextrin. (1). MC-YR $(25 \mu \mathrm{g} / \mathrm{mL}) ; 2$. MC-LR $(50 \mu \mathrm{g} / \mathrm{mL}) ; 3$. MC-LA $(25 \mu \mathrm{g} / \mathrm{mL})$. 


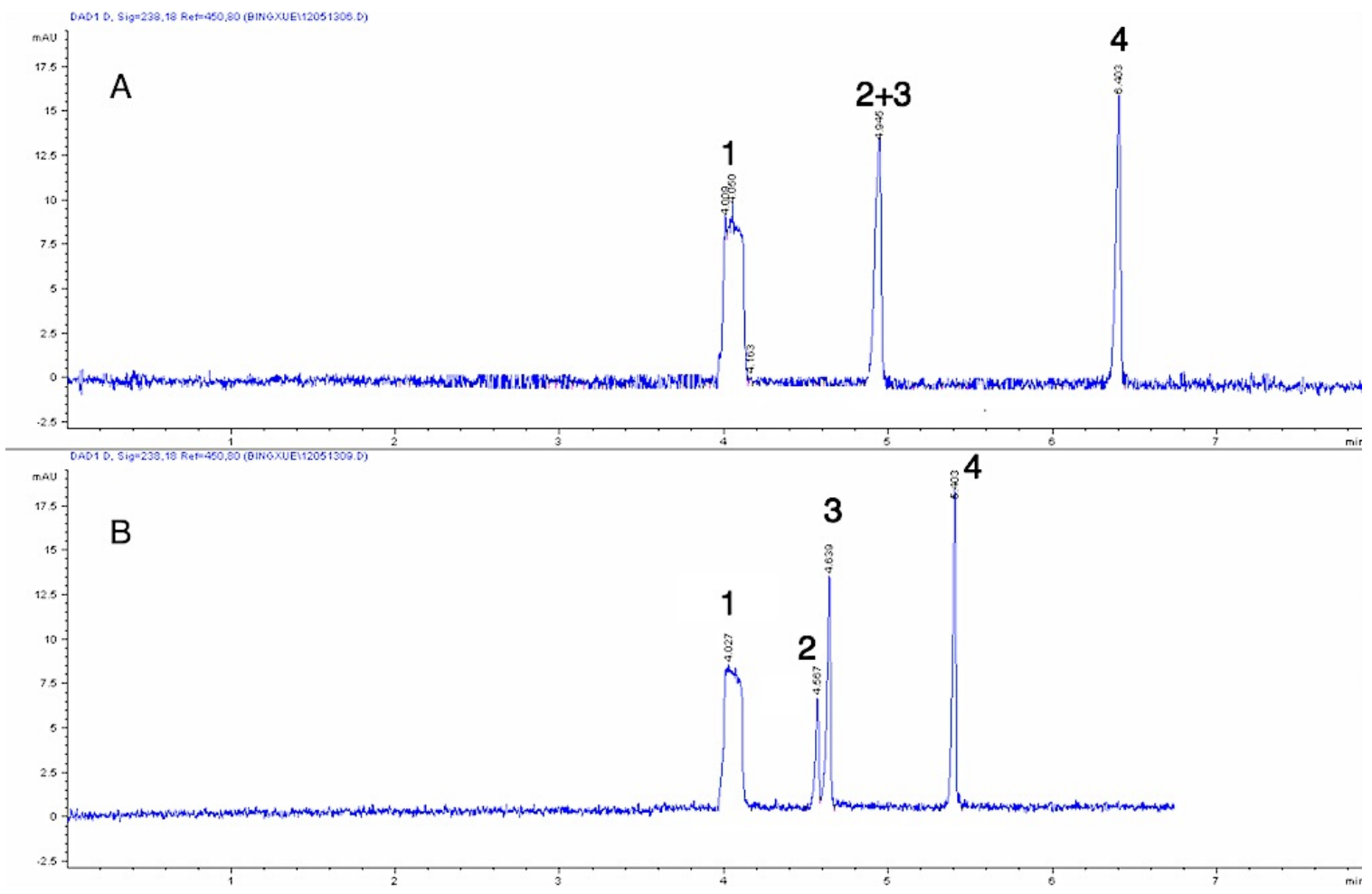

Fig. 12 Electropherograms of separation of four MCs mixture: (A). Without addition of $\beta$-cyclodextrin; (B). With addition of $20 \mathrm{mM} \beta$-cyclodextrin. (1). MC-RR (15 $\mu \mathrm{g} / \mathrm{mL})$;

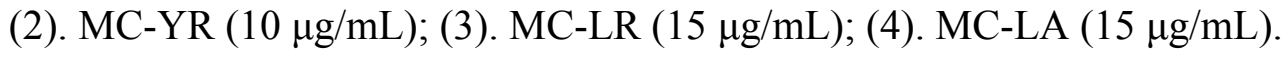

The previous study demonstrates that $\alpha$-CD did not produce significant complexation with MCs. This is apparently because the cavity of $\alpha-\mathrm{CD}$ is too small to complex with Adda chain. ${ }^{64}$ With the addition of $\alpha$-CD, the co-eluting analytes were not separated and the migration time of each analyte did not change significantly. This result was consistent with previous study. $\beta$ - and $\gamma$-CD were reported to complex better with MCs. ${ }^{64}$ However, the addition of $\gamma$-CD did not help with the separation significantly (Fig 13 A). Sulfated $\beta$-, and highly sulfated $\gamma$-CD were also investigated because of the possibility of coupling to mass spectrometry. CDs are cyclic oligosaccharides. These ionic species are not volatile, and thus are not suitable for the application of mass 
spectrometry. However, the sulfated-CD possesses negative charge over the entire $\mathrm{pH}$ range, thus in positive electrospray mode, these ions will be repelled and not spray into the mass spectrometer. In addition they will migrate counter to the EOF in the CE instrument. However, because MCs possess acidic $\mathrm{COOH}$ groups, a weak binding with negatively charged analytes was expected, and the sulfated-CD did not show selectivity in separation (Fig 13 B).

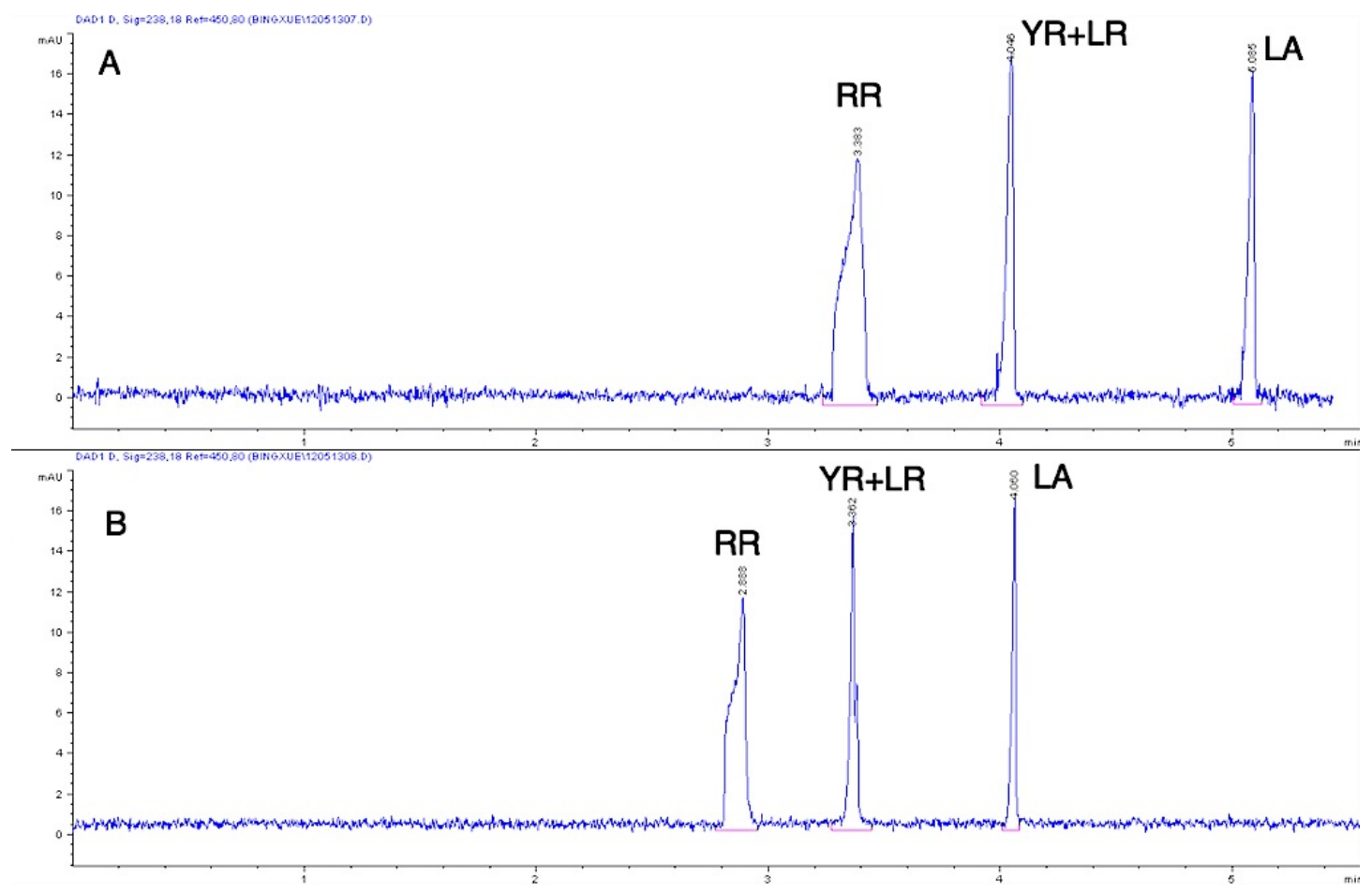

Fig. 13 Influences of different cyclodextrins: (A). $20 \mathrm{mM} \gamma$-cyclodextrin; (B). $20 \mathrm{mM}$ sulfated $\beta$-cyclodextrin.

\subsection{2 pH influence}

In capillary electrophoresis, the effect of EOF can facilitate the separation of cations, anions, and neutral molecules. Since $\mathrm{pH}$ significantly alters the EOF, as well as molecular charge, its influence on the separation of MCs was investigated. At low $\mathrm{pH}$, MCs are positively charged and EOF is decreased. Thus, all species migrate towards the 
cathode slowly. At high $\mathrm{pH}$, all the MCs are negatively charged. Despite the fact that the electrophoretic migration of the MCs is towards the anode, EOF is sufficiently strong and all MCs are swept towards the cathode. The cations migrate faster than neutrals and anions elute the last.

Below pH 3.5, all species were positively charged and migrate before the EOF. Above $\mathrm{pH}$ 3.5, MCs possess an overall negative charges and the EOF pushes the analytes to cathode. As shown in Fig 15, $\mathrm{pH}$ significantly affected the migration time. At $\mathrm{pH}$ lower than 3.50, the separation took more than 30 minutes to complete (result not shown). The higher the $\mathrm{pH}$, the faster the separation occurred. As the $\mathrm{pH}$ was increased, EOF increased significantly and elution occurred faster. At alkaline condition, the migration time of all species was significantly faster than at acidic conditions (Fig. 14). The overall separation was completed in less than 5 minutes at $\mathrm{pH}$ of 8.50 (Fig. 15).

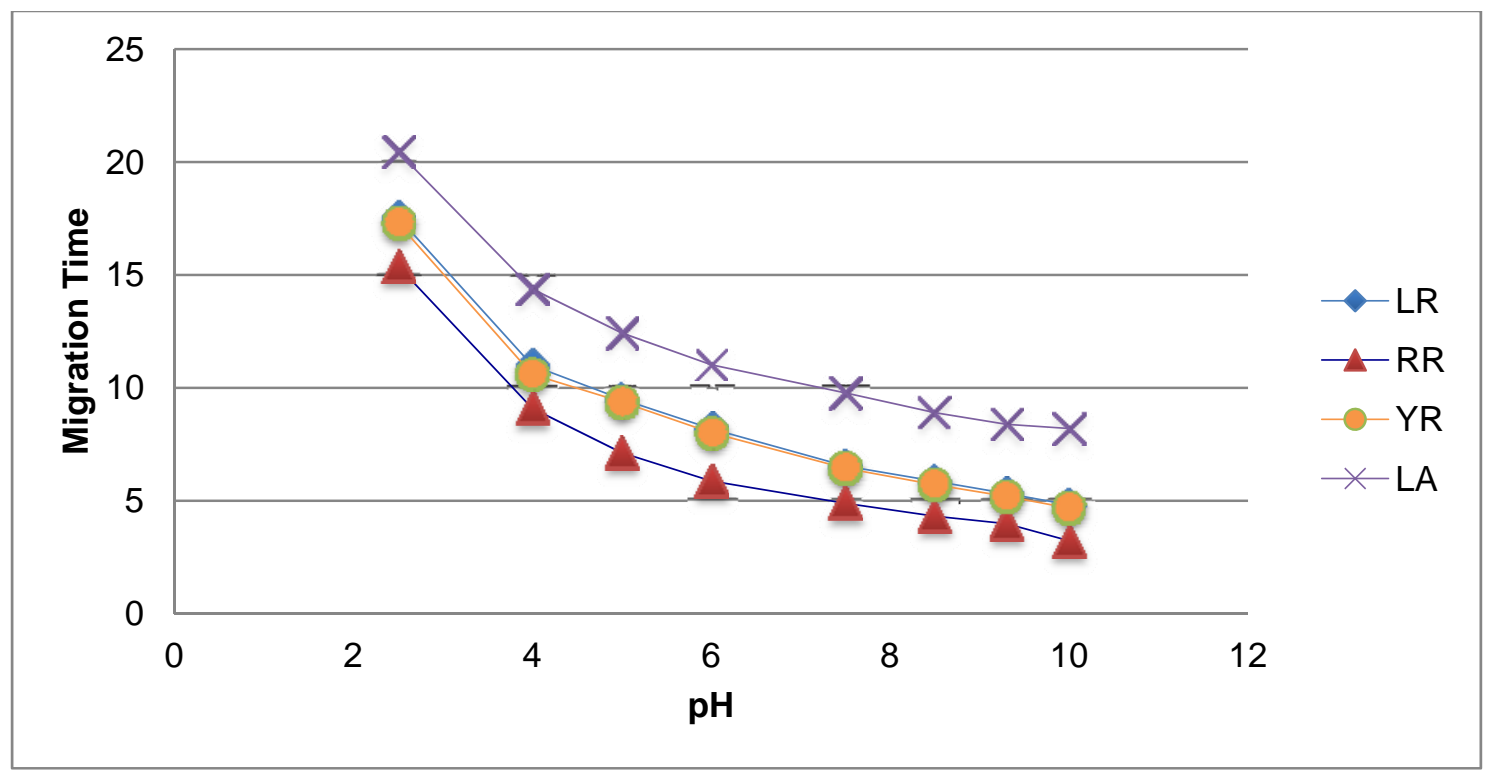

Fig. 14 Influences of the migration of microcystins on the $\mathrm{pH}$ of buffer electrolyte. Analytes were tested in $50 \mathrm{mM}$ sodium phosphate with various $\mathrm{pHs}$ from 2.0 to 10.0 . 

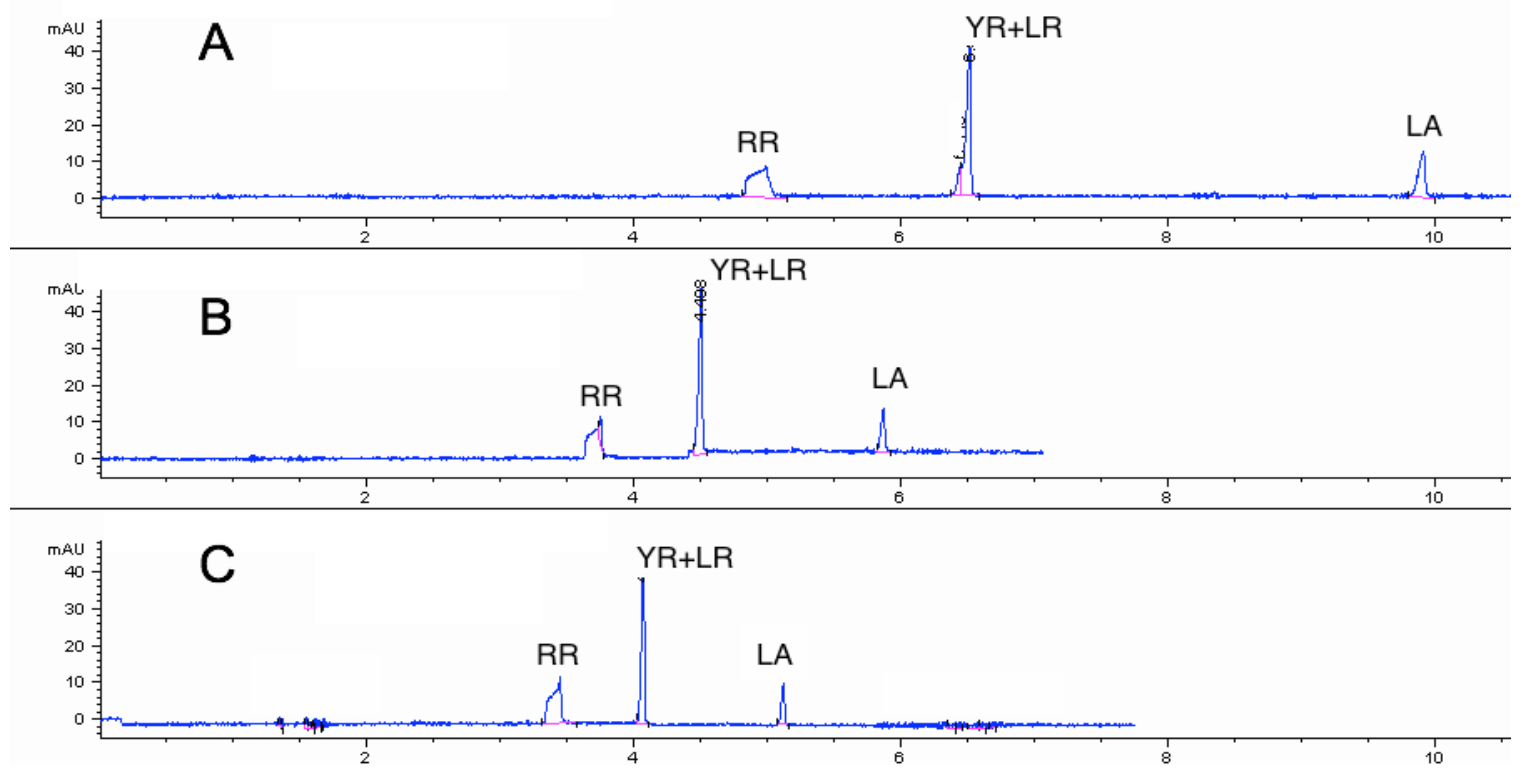

Fig. 15 Electropherograms of separation in various $\mathrm{pH}$ : (A). $\mathrm{pH}=6.00 ;(\mathrm{B}) \cdot \mathrm{pH}=7.50$; (C). $\mathrm{pH}=8.50$. Buffer: $50 \mathrm{mM}$ sodium phosphate without addition of $\beta$-cyclodextrin.

Higher pHs were also studied and were expected to shorten the separation (Fig. 16). Interestingly, at pHs higher than 9.30, MC-LR and MC-YR began to resolve without any addictive in the buffer electrolyte. The resolution of the two peaks improved as the $\mathrm{pH}$ increased to 9.90. Therefore, the optimal $\mathrm{pH}$ for the separation was set at a $\mathrm{pH}$ of 9.30 using $50 \mathrm{mM}$ sodium phosphate.

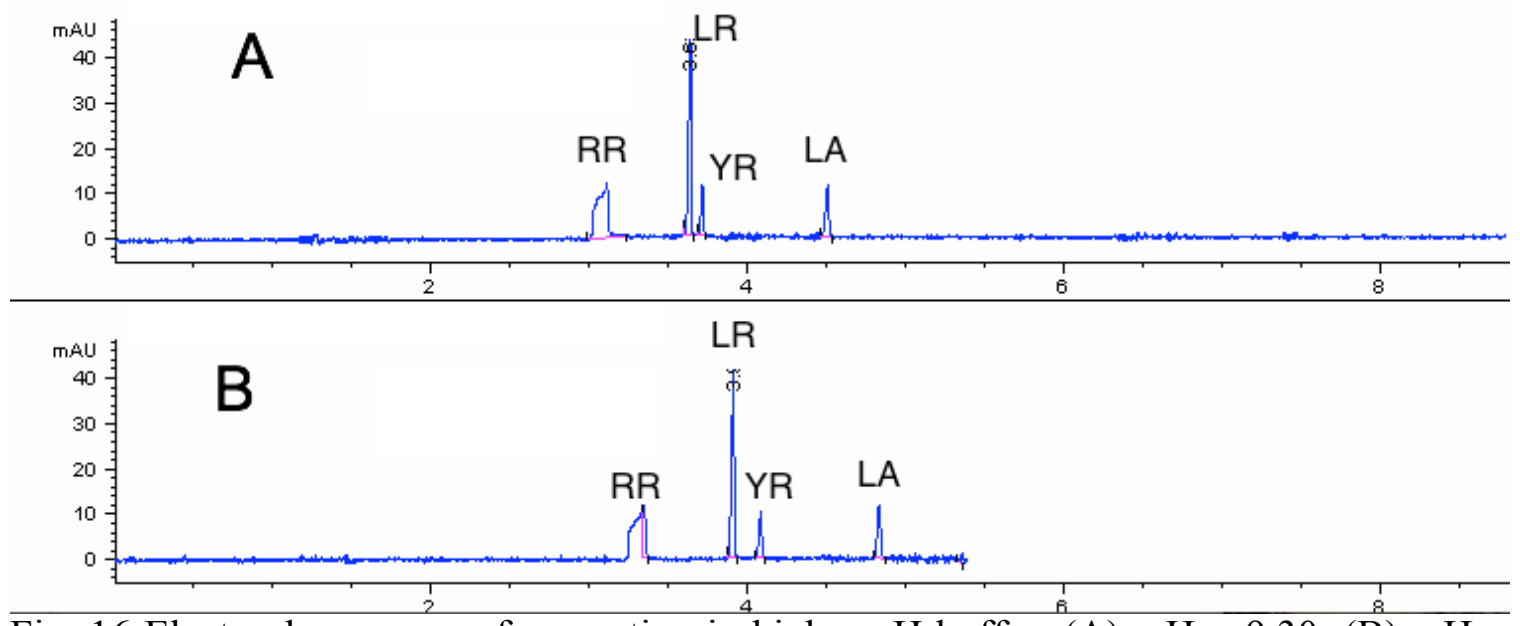

Fig. 16 Electropherograms of separation in higher $\mathrm{pH}$ buffer: $(\mathrm{A}) \cdot \mathrm{pH}=9.30 ;(\mathrm{B}) \cdot \mathrm{pH}=$ 
9.90. Buffer: $50 \mathrm{mM}$ sodium phosphate without addition of $\beta$-cyclodextrin, $\lambda=240 \mathrm{~nm}$, voltage $=25 \mathrm{Kv}$.

At a $\mathrm{pH}$ of 9.30, the elution order of MC-YR and MC-LR was observed to change upon addition of $\beta$-CD (Fig. 17). In experiments without $\beta-C D, M C-Y R$ was eluted after MC-LR. However, when $\beta$-CD was added, MC-YR was eluted before MC-LR. In the cyclodextrin study and $\mathrm{pH}$ study, the addition of $\beta-\mathrm{CD}$ was needed to resolve MC-YR and MC-LR at low $\mathrm{pH}(<9.30)$, whereas $\beta$-CD was not necessarily needed to resolve the co-eluting peaks at high $\mathrm{pH}(>9.30)$. Because $\beta-\mathrm{CD}$ is detrimental to $\mathrm{MS}$ analysis, this was a useful result for subsequent analysis by electrospray-MS.
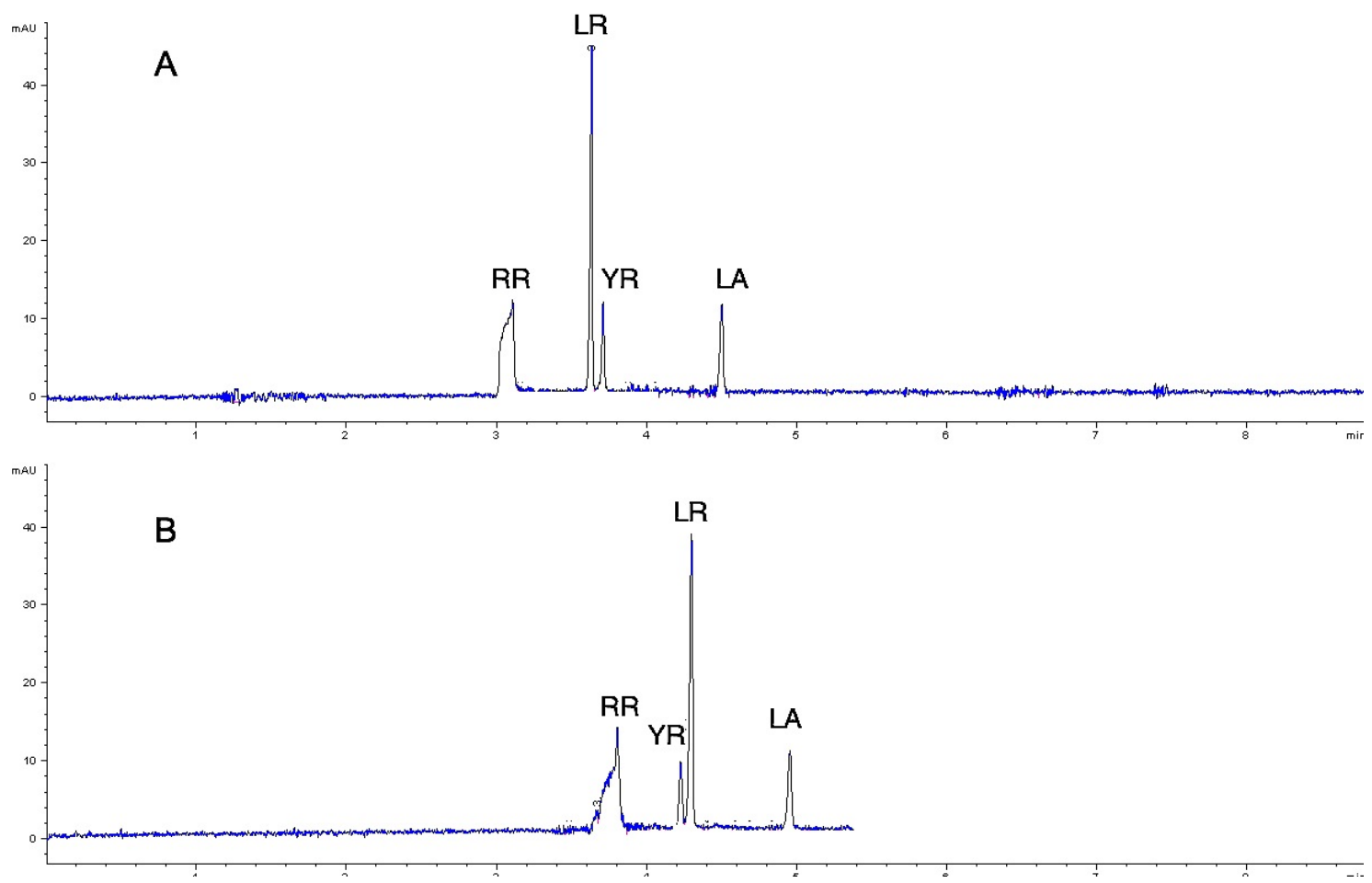

Fig. 17 The change of elution order when $\beta$-cyclodextrin was added into the buffer electrolyte, $\mathrm{pH}=9.30$ : (A). Buffer: $50 \mathrm{mM}$ sodium phosphate without $\beta$-cyclodextrin; (B) Buffer: $50 \mathrm{mM}$ sodium phosphate with $20 \mathrm{mM} \beta$-cyclodextrin. 


\subsubsection{Effects of buffer electrolyte ionic strength}

In capillary electrophoresis, an increase in buffer ionic strength decreases EOF. Increasing the ionic strength was expected to decrease the mobility of analytes, thus increasing the migration time. The influence of background electrolyte ionic strength on migration of MCs is shown in Fig. 18. Modest improvement of resolution was shown as the ionic strength of background electrolyte was increased. Considering the migration time and separation efficiency, $50 \mathrm{mM}$ of sodium phosphate was chosen for the optimal background electrolyte concentration. At greater ionic strength, the current of $\mathrm{CE}$ instrument tends to increase rapidly which could potentially result in capillary breakage and instrument problems.

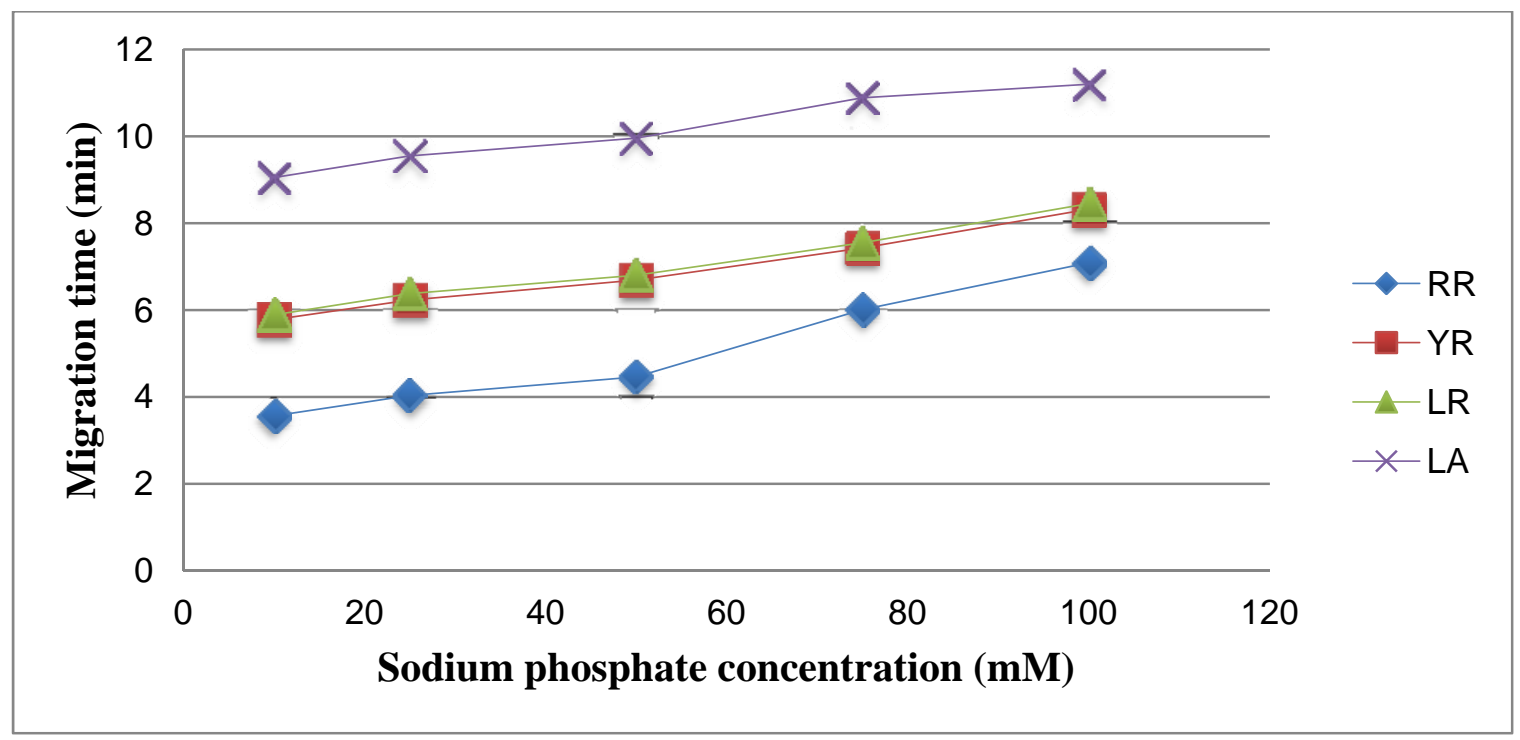

Fig. 18 Migration of microcystins affected by sodium phosphate concentrations. Analytes were tested in $\mathrm{pH} 9.30$ sodium phosphate with various concentrations from 10 to $100 \mathrm{mM}$

\subsection{Analytical performance}

The proposed CE-UV separation method was evaluated in terms of limit of detection (LOD), limit of quantification (LOQ), linearity, precision, and linear range. The 
optimal buffer electrolyte was $50 \mathrm{mM}$ sodium phosphate and the buffer $\mathrm{pH}$ was maintained 9.30. The optimal detection wavelength for all MCs was $240 \mathrm{~nm}$, and the optimal CE voltage was $25 \mathrm{KV}$. The LOD, LOQ, and precision value are summarized in Table 2. The calculations of LOD and LOQ were based on the standard deviation of ten minimal detectable signals. The RSD value of the migration times and peak areas were obtained from ten repeated measurements. The precision of the migration times was less than $1 \%$ RSD and the precision of peak areas was only slightly larger, indicating that the separation method was relatively stable. The linear regression for all the toxins was calculated from five different concentrations and five replicates for each concentration. Table 2. Analytical parameters of CE-UV determination of microcystins.

\begin{tabular}{ccccccc}
\hline Compound & $\begin{array}{c}\text { LOD } \\
(\mu \mathrm{g} / \mathrm{mL})\end{array}$ & $\begin{array}{c}\text { LOQ } \\
(\mu \mathrm{g} / \mathrm{mL})\end{array}$ & $\mathrm{R}^{2}$ & Slope & $\begin{array}{c}\text { RSD, } \% \\
\text { peak area }\end{array}$ & $\begin{array}{c}\text { RSD, \% } \\
\text { migration } \\
\text { time }\end{array}$ \\
\hline MC-RR & 1.25 & 3.75 & 0.99663 & 0.80390 & 1.97 & 0.23 \\
MC-LR & 0.92 & 2.77 & 0.99773 & 0.65560 & 1.03 & 0.28 \\
MC-YR & 2.25 & 6.75 & 0.98328 & 0.16720 & 1.42 & 0.42 \\
MC-LA & 2.17 & 6.51 & 0.96109 & 0.20270 & 1.37 & 0.35 \\
\hline
\end{tabular}

The linear regression for all the toxins was calculated from five different concentrations and five replicates for each concentration. The calibration curve is sketched in Fig. 19. The peak area was found to be in linear relationship with concentration of analytes. The $\mathrm{R}^{2}$ values of all analytes are close to 1 indicating the $\mathrm{CE}$ method was suitable for MCs analysis. 


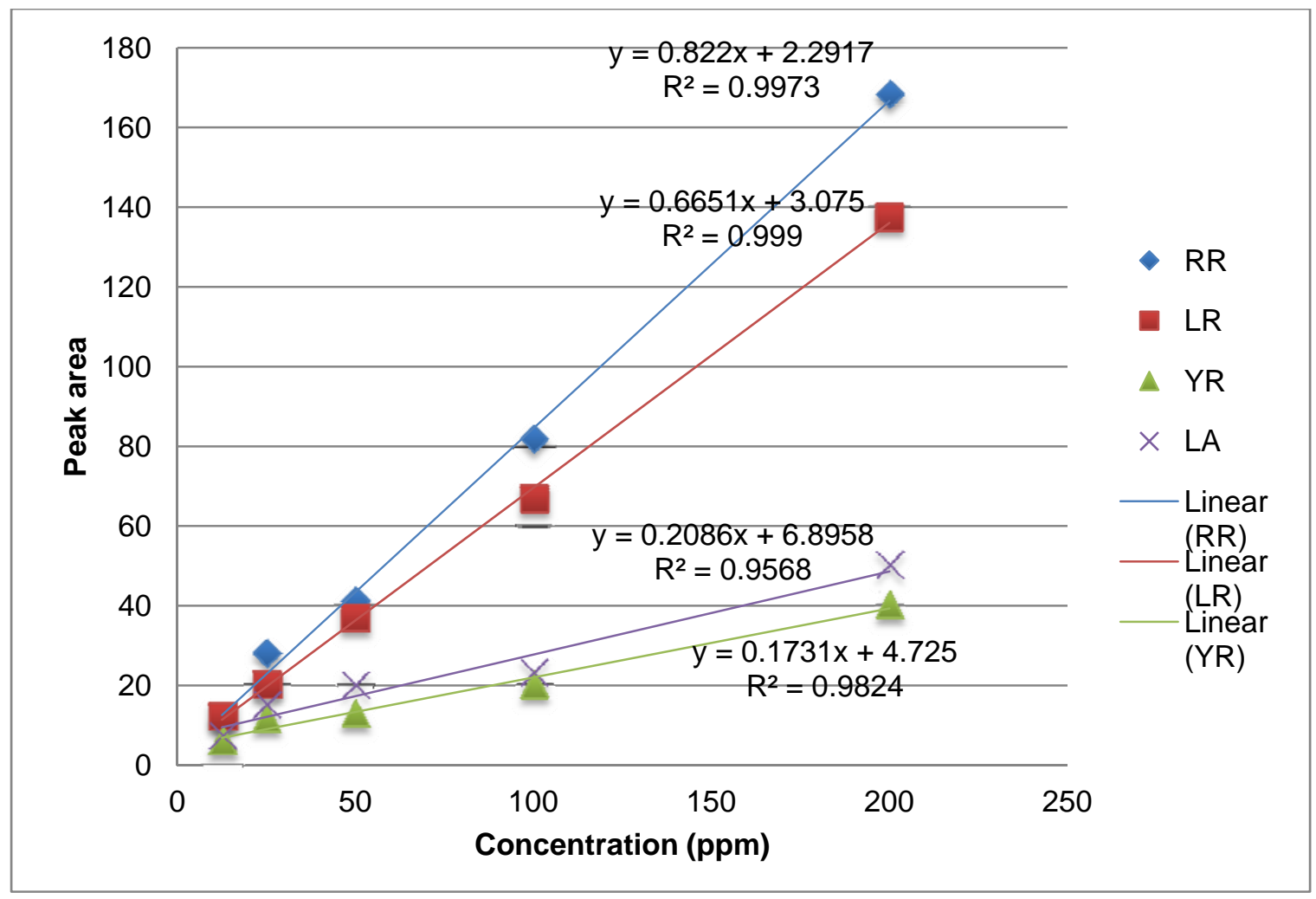

Fig. 19 Linearity of CE determination of microcystins. Buffer: $50 \mathrm{mM}$ sodium phosphate, pH 9.30. $\lambda=240 \mathrm{~nm}$, voltage $=25 \mathrm{KV}$.

\subsection{CE-MS identification}

Mass spectrometry can provide the accurate information on molecular weight and molecular structure. The off-line ESI-MS was used to identify MCs. ${ }^{65}$ However, no research was focusing the on-line CE-MS determination of MCs. In this research, CE coupled with ESI-TOF was developed for the determination of MCs in environmental algal blooms. With the optimized CE separation condition, ESI-TOF parameters were investigated in order to achieve better sensitivity. The major requirement for MS optimization was the compatibility with on-line ESI-TOF detection. The optimized CE conditions were directly applied on the CE-MS detection using a sheath flow liquid consisting of methanol/water (50:50, v:v) as sheath liquid with a flow rate of $3 \mu \mathrm{L} / \mathrm{min}$. 
The background electrolyte was $50 \mathrm{mM}$ sodium phosphate, $\mathrm{pH}$ 9.30. Unfortunately at this $\mathrm{pH}$, no useful MS data was obtained. One potential reason could be at the high $\mathrm{pH}$ (9.30) of sodium phosphate, analytes were not ionized efficiently and few analyte were spayed into the MS. Another reason may be ion suppression from the relatively high salt content. Therefore, a buffer $\mathrm{pH}$ of 8.50 without the addition of $\beta-\mathrm{CD}$ was used in the CE-MS analysis. As expected, MC-YR and MC-LR coeluted, however, the co-eluting analytes could be differentiated by the different $\mathrm{m} / \mathrm{z}$ ratio of the two parent ions (Fig. 20). With MC-LR showing a $[\mathrm{M}+\mathrm{H}]^{+}$ion at $\mathrm{m} / \mathrm{z}$ of 995.5609 and MC-YR showing a $[\mathrm{M}+\mathrm{H}]^{+}$ion at with $\mathrm{m} / \mathrm{z}$ of 1045.5362. MC-RR showed a $[\mathrm{M}+\mathrm{H}]^{+}$ion at a $\mathrm{m} / \mathrm{z}$ of 1038.5911 and it also showed a characteristic doubly charged $[\mathrm{M}+2 \mathrm{H}]^{2+}$ with $\mathrm{m} / \mathrm{z}$ of 519.7998 (Fig 21). This $[\mathrm{M}+2 \mathrm{H}]^{2+}$ fragment could be very useful to identify MC-RR. MC-LA showed $[\mathrm{M}+\mathrm{H}]^{+}$ with $\mathrm{m} / \mathrm{z}$ of 910.5175 . The mass errors were listed in Table 3. For all the MCs, mass errors were less than $30 \mathrm{ppm}$. The obtained results showed the CE-ESI-TOF method could be potentially used in the analysis of crude algae samples.

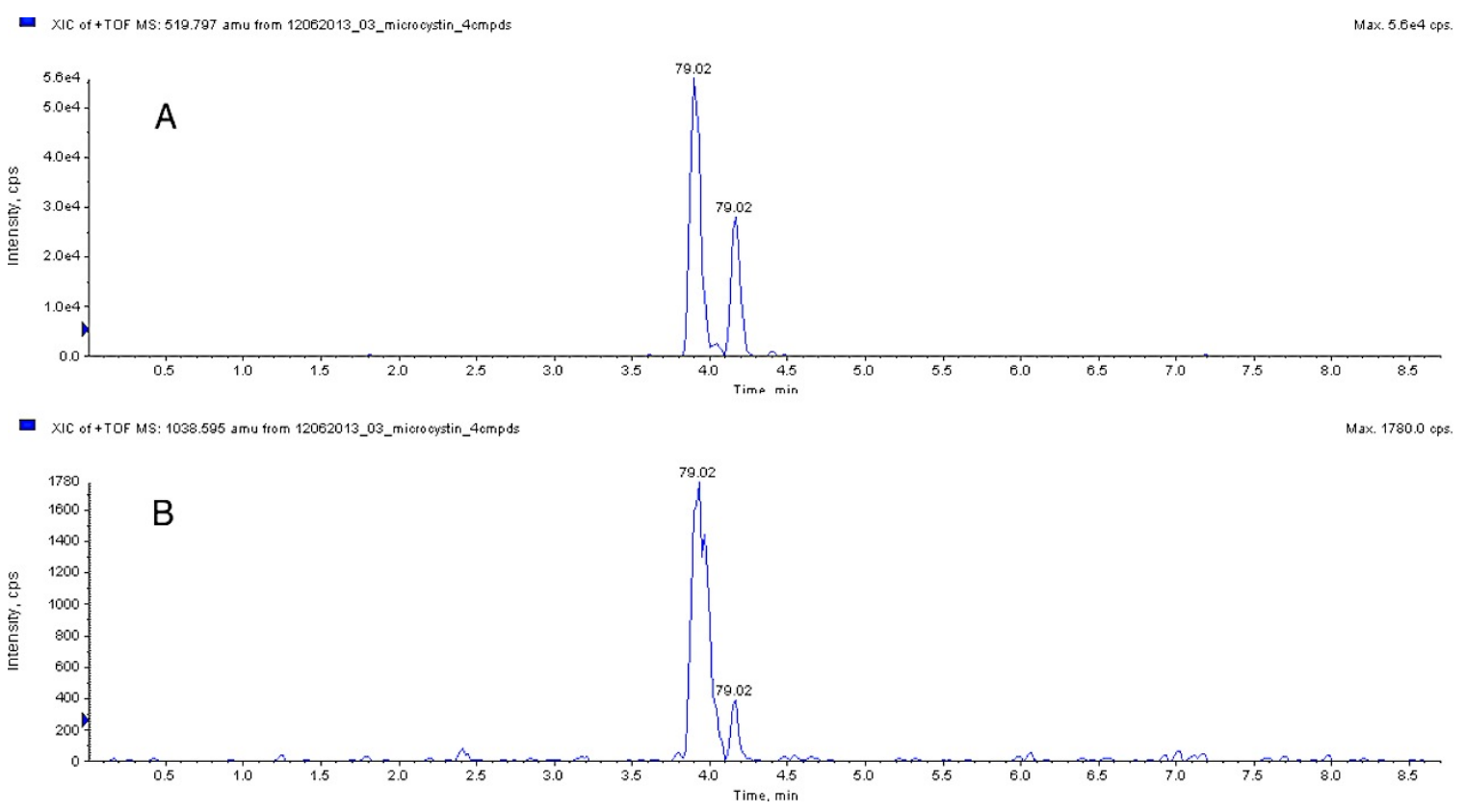


a XIC of +TOF MS: 1045.533 amu from 12062013_03_microcystin_4cmpds

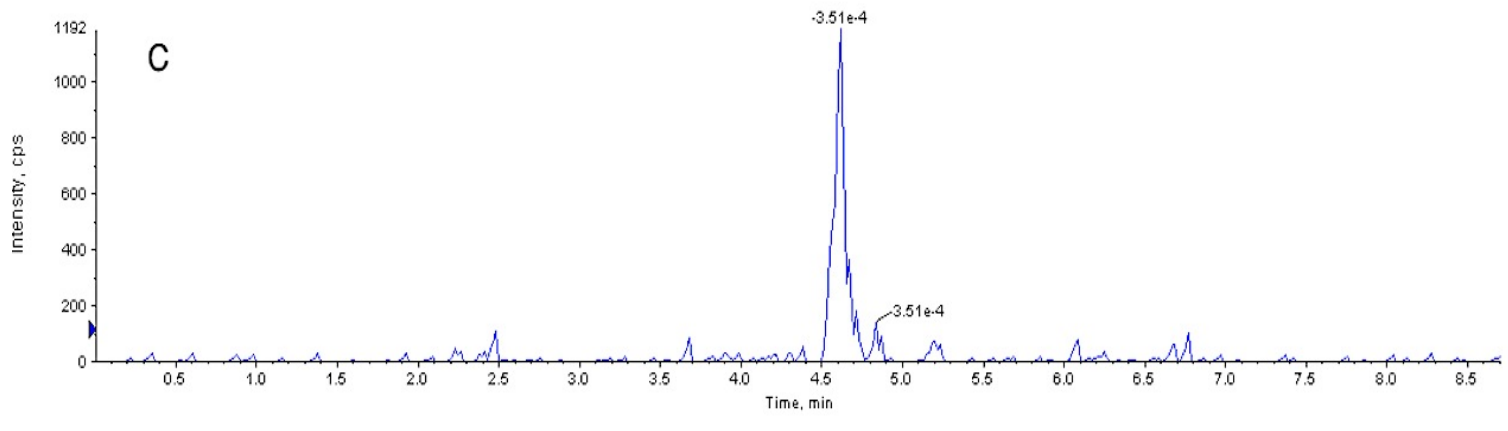

a XIC of +TOF MS: 810.511 amu from 12062013_03_microcystin_4cmpds

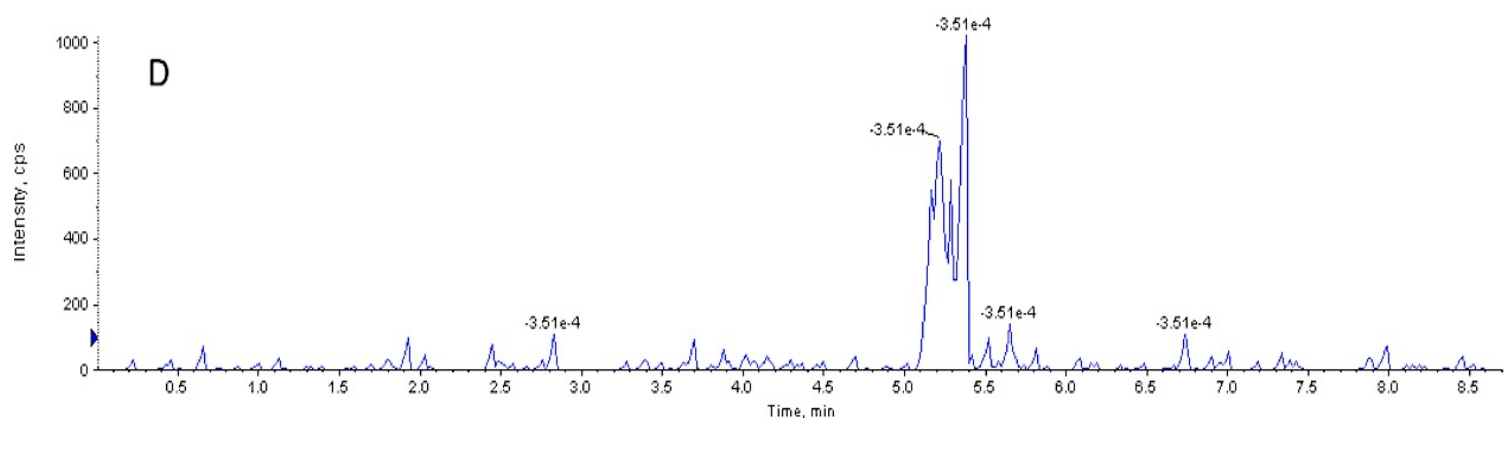

- XIC of +TOF MS: 995.566 amu from 12062013_03_microcystin_4cmpds

Max. $2239.1 \mathrm{cps}$.

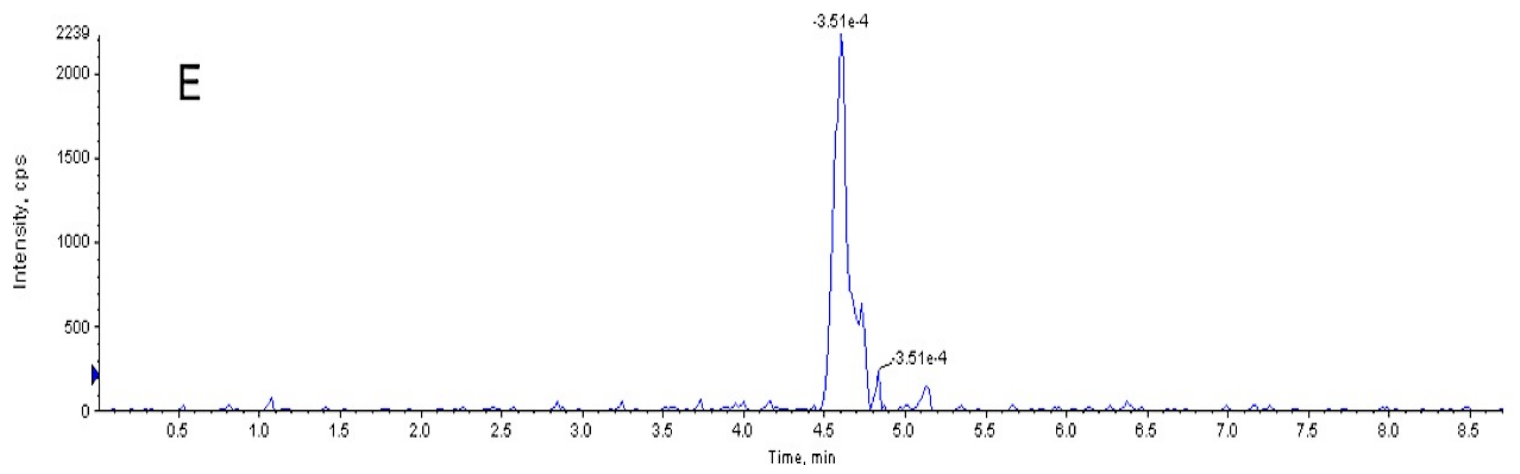

Fig. 20 Extracted Ion Chromatograms of microcystins: (A). MC-RR $\left([\mathrm{M}+2 \mathrm{H}]^{2+}\right.$ ion 519.8033); (B). MC-RR ([M+H $]^{+}$ion 1038.6067); (C). MC-YR ([M+H $]^{+}$ion 1045.5452); (D). MC-LA ([M+H $]^{+}$ion 910.5190; (E). MC-LR $\left([\mathrm{M}+\mathrm{H}]^{+}\right.$ion 995.5769. Buffer for CEMS: $50 \mathrm{mM}$ sodium phosphate, $\mathrm{pH}=8.50$. Positive ion mode, sheath liquid methanol/water (50:50, v:v). 


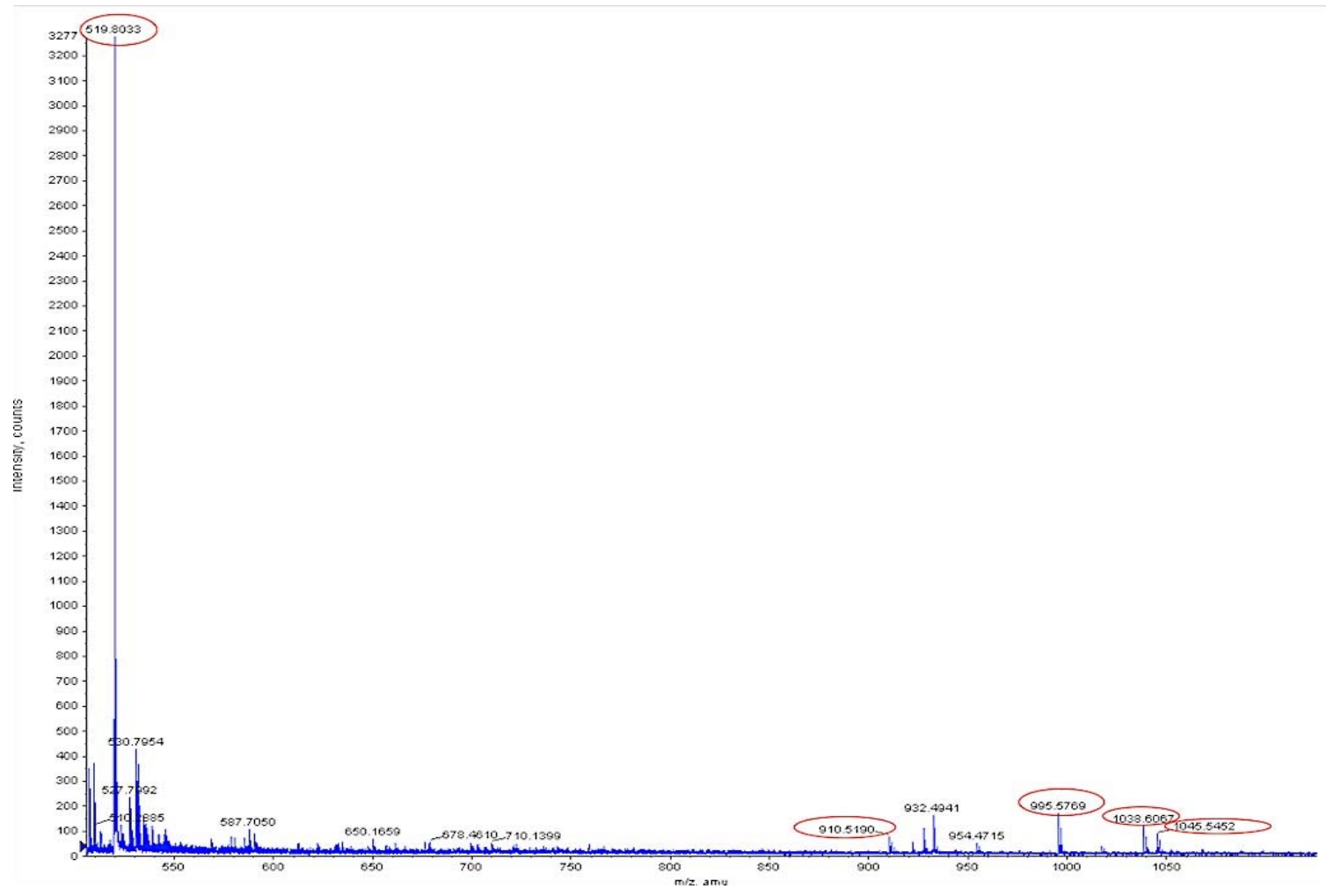

Fig. 21 Mass spectrum of four analytes. [MC-LA+H] 910.5109, [MC-YR+H] 1045.5452, [MC-LR+H] 995.5769, [MC-RR+H] 1038.6067, [MC-RR+2H] 519.8033. Positive ion mode, sheath liquid methanol/water (50:50, v:v).

Table 3. Mass results of microcystins.

\begin{tabular}{ccccc}
\hline Compound & Theoretical m/z & Experimental m/z & Error (amu) & Error (ppm) \\
\hline MC-RR & 1038.5719 & 1038.5911 & 0.0192 & 18 \\
MC-LR & 995.5548 & 995.5609 & 0.0061 & 6 \\
MC-YR & 1045.5341 & 1045.5362 & 0.0021 & 2 \\
MC-LA & 910.4909 & 910.5175 & 0.0266 & 29 \\
\hline
\end{tabular}




\subsection{Analysis of environmental samples}

\subsubsection{Analysis of spiked water sample}

The developed CE methods were next tested on the spiked lake water samples. A mixture consisting of $5.0 \mu \mathrm{g}$ MC-LR, $5.0 \mu \mathrm{g}$ MC-RR, 1.0 $\mu \mathrm{g}$ MC-LA, 1.0 $\mu \mathrm{g}$ MC-YR was spiked into $10 \mathrm{~mL}$ lake water and extracted as described in the experimental section and eluted with $2 \mathrm{~mL}$ methanol. The eluted sample was dried by a steam of nitrogen and reconstituted in $200 \mu \mathrm{L}$ of methanol. The recovery was calculated based on the calibration curve. The percent recovery of MC-RR, MC-LR, MC-YR, and MC-LA was calculated to be $78.65 \%, 82.43 \%, 60.12 \%$, and $70.33 \%$ respectively.

The reproducibility was evaluated by testing the extracted MCs in five replicates. All the MCs were detected by CE-UV and good reproducibility was obtained (Fig. 22). The CE-MS analysis was carried out with $50 \mathrm{mM}$ sodium phosphate with $\mathrm{pH}$ of 8.50 , with no addition of CDs. All four microcystins were detected in five replicates with good reproducibility (Fig. 23).

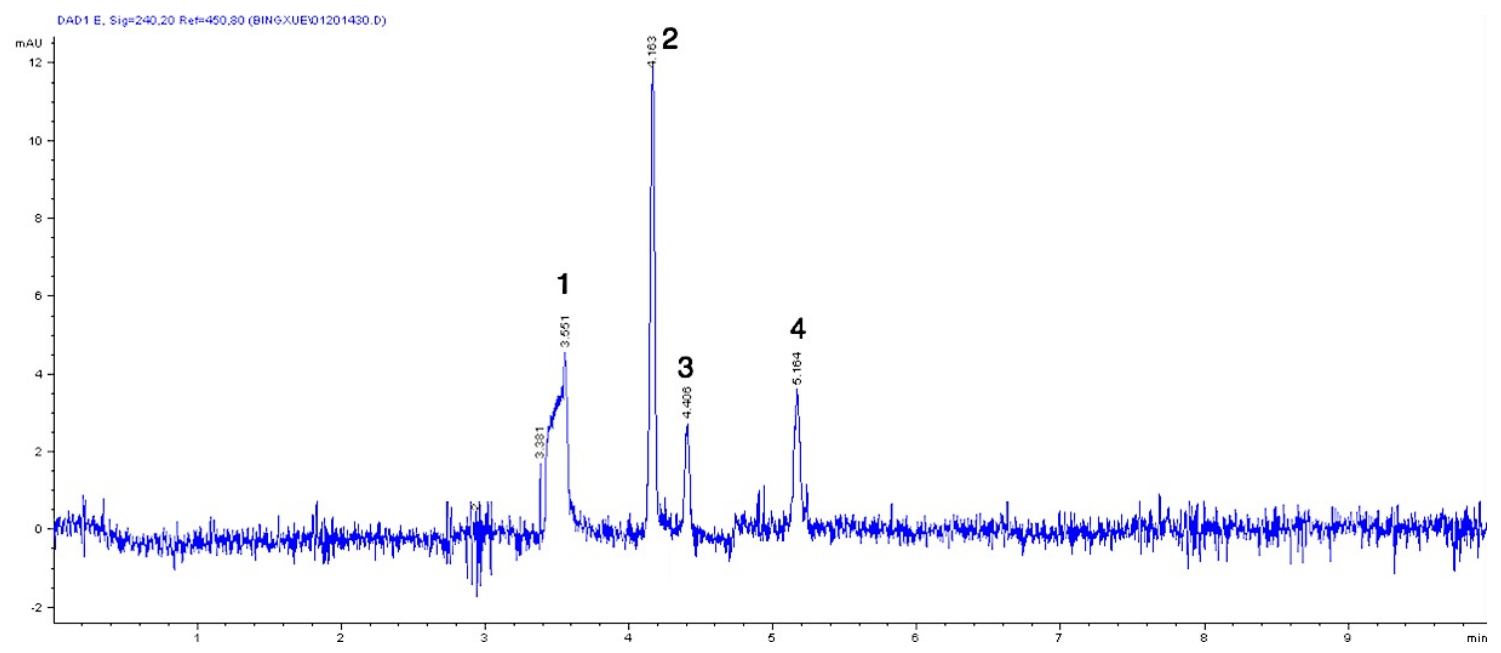

Fig. $22 \mathrm{CE}$ separation of spiked standards in drinking water plant sample in North Carolina: (1). MC-RR (25 $\mu \mathrm{g} / \mathrm{mL})$ and (2). MC-LR $(25 \mu \mathrm{g} / \mathrm{mL}) ;(3) . \mathrm{MC}-\mathrm{YR}(10 \mu \mathrm{g} / \mathrm{mL})$ 
and (4). MC-LA (10 $\mu \mathrm{g} / \mathrm{mL})$. Buffer: $50 \mathrm{mM}$ sodium phosphate without addition of $\beta$ cyclodextrin, $\mathrm{pH}=9.30, \lambda=240 \mathrm{~nm}, \mathrm{CE}$ voltage $=25 \mathrm{KV}$.

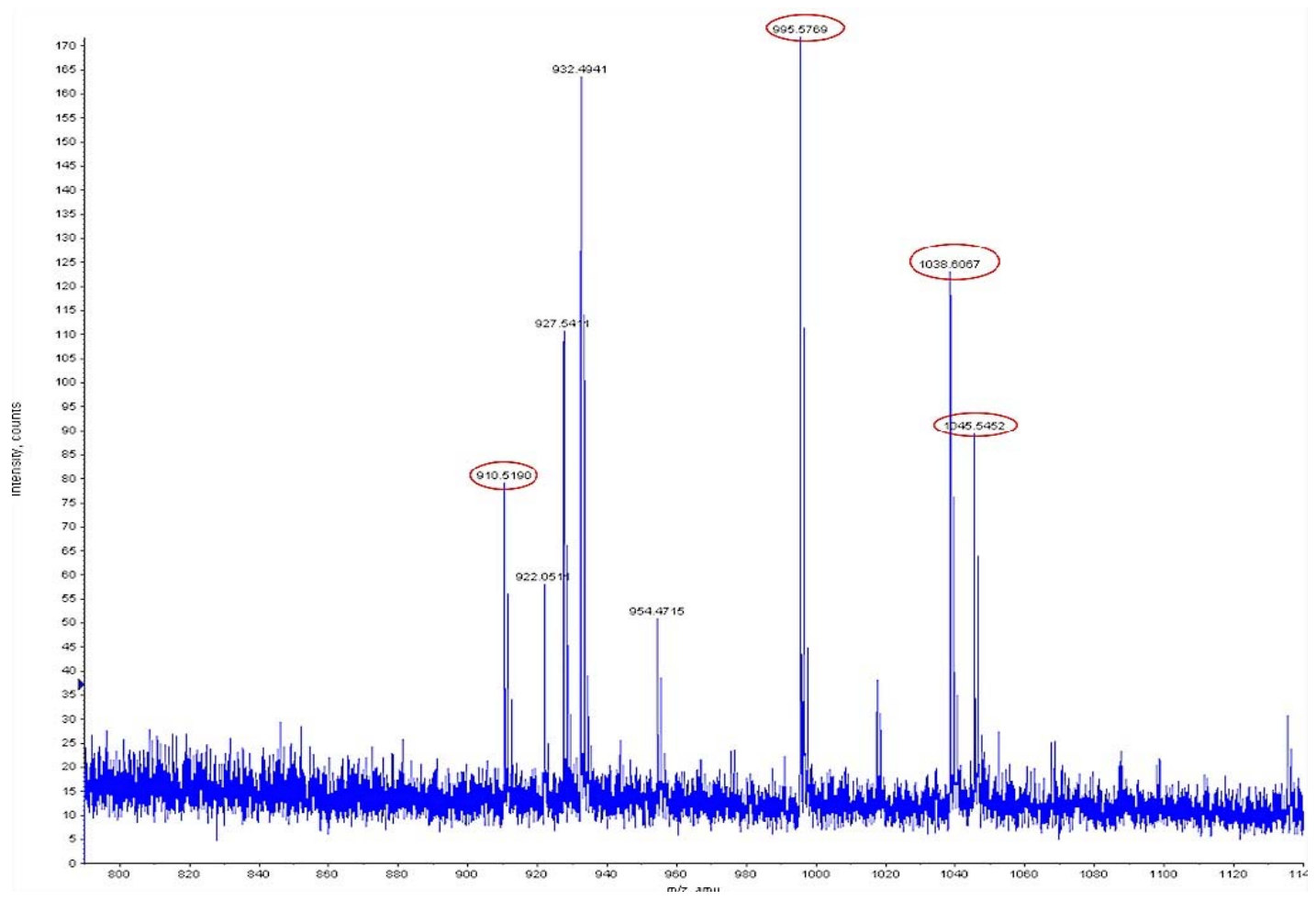

Fig. 23 CE-MS spectrum of microcystins spiked in drinking water plan sample in North Carolina. [MC-LA+H] 910.5109, [MC-YR+H] 1045.5452, [MC-LR+H] 995.5769, [MC$\mathrm{RR}+\mathrm{H}]$ 1038.6067. Positive ion mode, sheath liquid methanol/water (50:50, v:v).

\subsubsection{Analysis of algal bloom samples}

The environmental water sample was extracted as previously described and tested by CE-UV and CE-MS methods. There were two positive results showing the presence of microcystins out of 17 environmental algal blooms. The algal bloom samples were collected at a drinking water plant in North Carolina. In bloom sample 4, MC-LR, MCYR, and MC-LA were detected by CE-UV and CE-MS (Fig. 26-27). The microcystin peaks could be identified according to the migration times and mass spectrum. In bloom 
sample 8 , no commonly found MCs were present. The mass spectrum showed an $\mathrm{m} / \mathrm{z}$ ion of 725.3704 which is in the molecular weight range of microcystin. The UV spectrum of this analyte was similar to the spectrum of a microcystin. The obtained results were checked by HPLC-MS/MS analysis, and HPLC results were consistent with CE results.

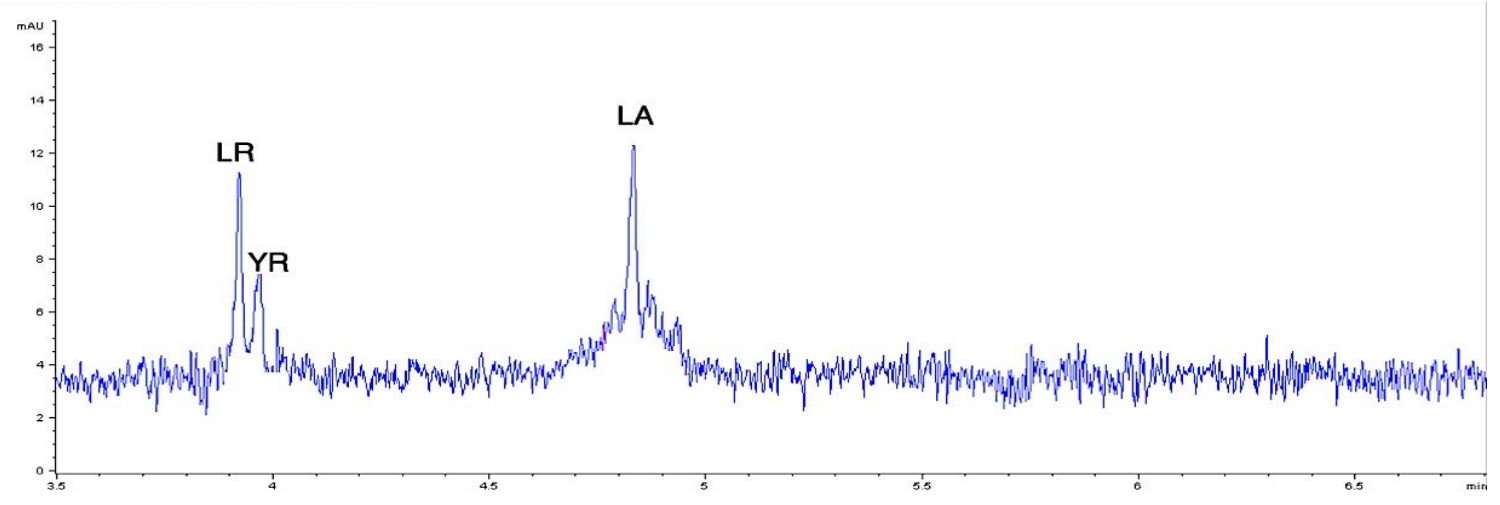

Fig. 24 Electropherogram of bloom sample 4 with CE method. Buffer: $50 \mathrm{mM}$ sodium phosphate, $\mathrm{pH} 9.3, \lambda=240 \mathrm{~nm}, \mathrm{CE}$ voltage $=25 \mathrm{kV}$.

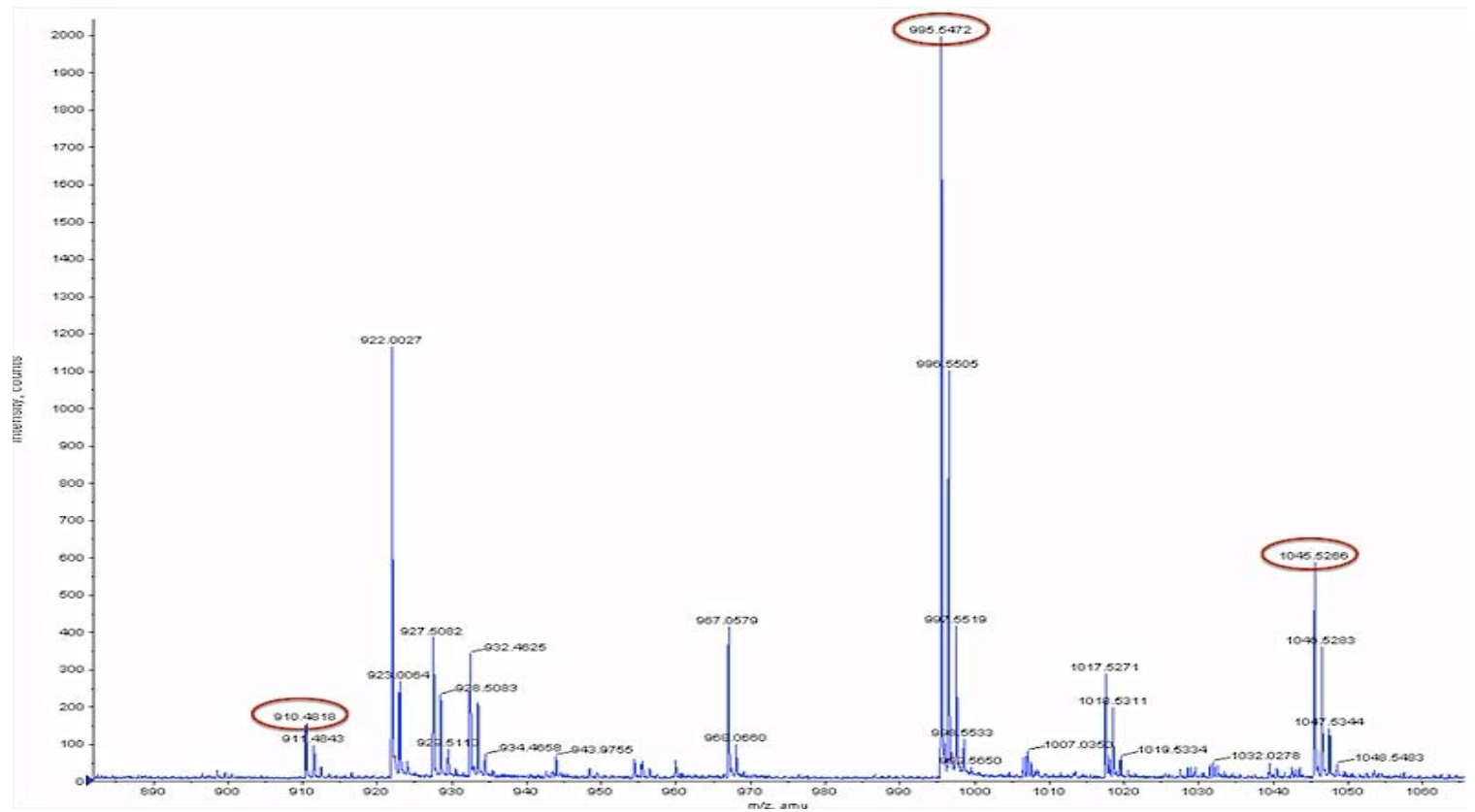

Fig. 25 Mass spectrum of bloom sample 4. [MC-LA+H] 910.4618, [MC-YR+H] 1045.5266, [MC-LR+H] 995.5472. Positive ion mode, sheath liquid methanol/water $(50: 50, v: v)$. 


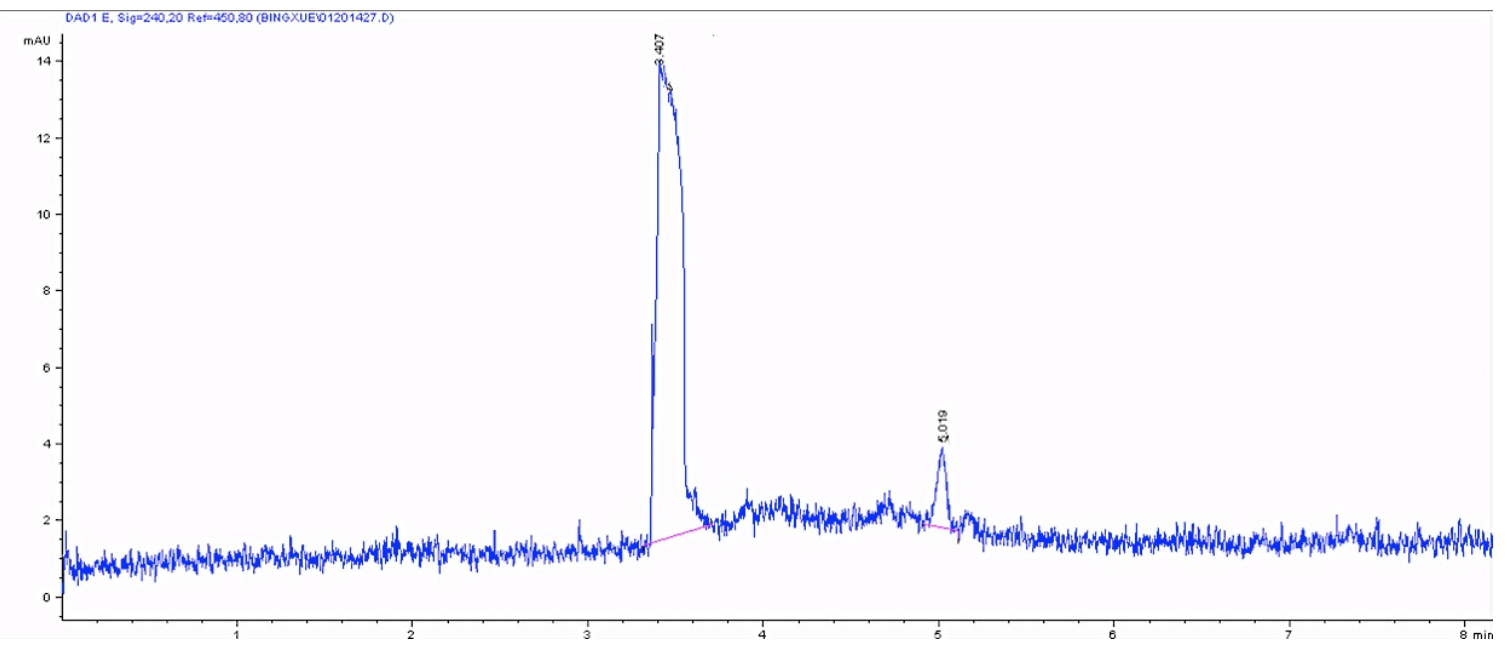

Fig. 26 Electropherogram of bloom sample 8 with CE method. Buffer: $50 \mathrm{mM}$ sodium phosphate, $\mathrm{pH} 9.3, \lambda=240 \mathrm{~nm}, \mathrm{CE}$ voltage $=25 \mathrm{kV}$.

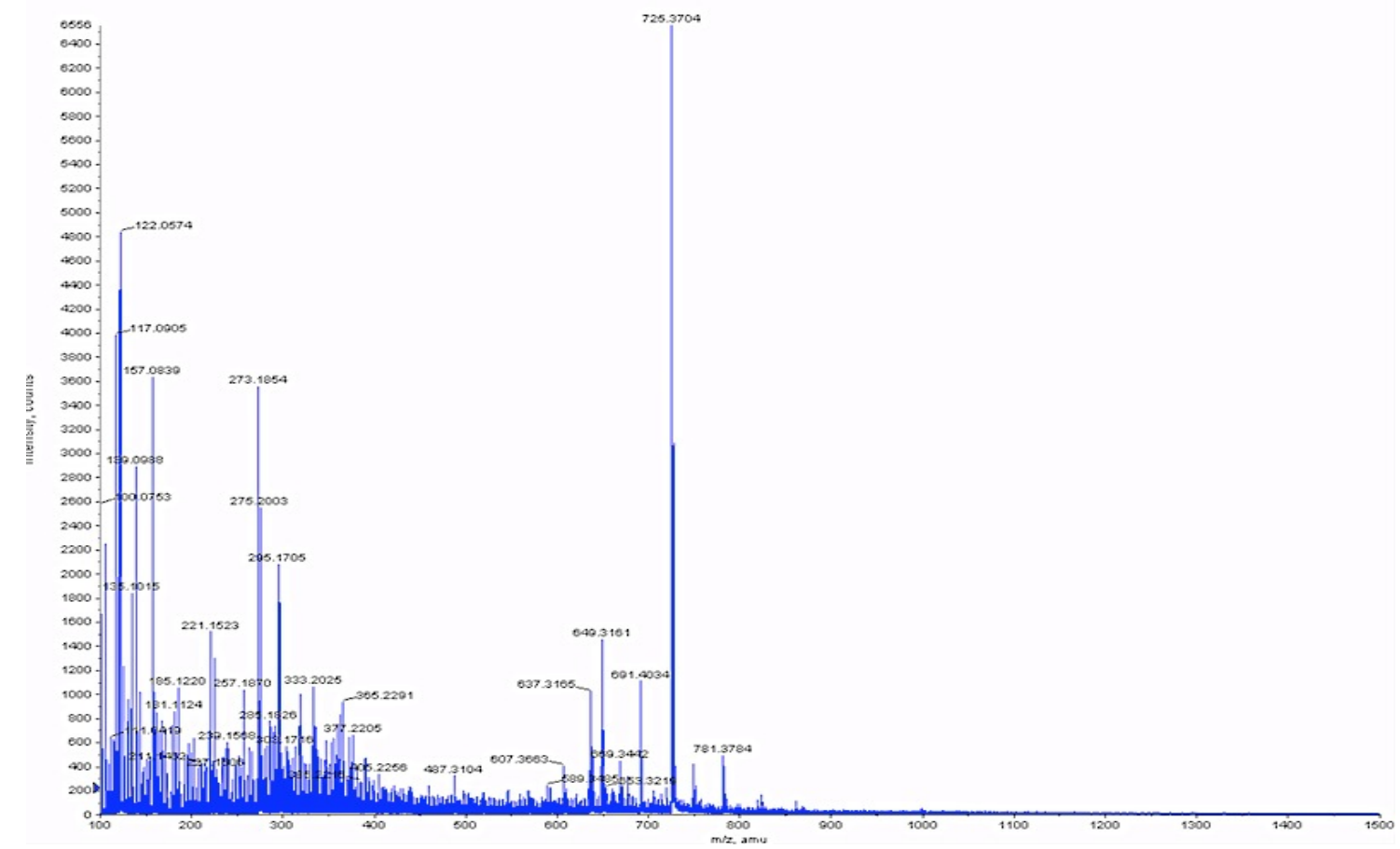

Fig. 27 Mass spectrum of bloom sample 8. $[\mathrm{M}+\mathrm{H}]$ 725.3704. Positive ion mode, sheath liquid methanol/water $(50: 50, \mathrm{v}: \mathrm{v})$. 


\section{CHAPTER 4}

\section{Conclusion and future work}

Methods utilizing CE and CE-MS have been developed for the determination of four frequently occurring microcystins (MC-RR, MC-YR, MC-LR, and MC-LA). The developed methods provided optimal separation of the microcystins in spiked lake water sample and also in algal bloom samples. Unlike previously reported chromatographic methods, these CE methods could be integrated into a microfluidic chip device and suitable for field applications. Furthermore, the method described here is the first to utilize cyclodextrins in the simultaneous separation of microcystins. The UV detection enabled the determination of microcystins in $\mathrm{mg} / \mathrm{mL}$ range.

The coupling of the CE separation with an ESI-TOF detector is a powerful tool to identify microcystins at lower detection limits. The developed CE method could not be used directly on CE-MS due to the high $\mathrm{pH}$ of buffer electrolyte is not preferable for the ionization of analytes and the occurrence of ion suppression. Therefore, sodium phosphate with $\mathrm{pH}$ of 8.50 was chosen to be the buffer electrolyte for CE-MS analysis. With this buffer electrolyte, MC-YR and MC-LR were co-eluting, but they can be differentiated by $\mathrm{m} / \mathrm{z}$ ions. Four different microcystins were identified based on the exact mass of the $[\mathrm{M}+\mathrm{H}]^{+}$and $[\mathrm{M}+2 \mathrm{H}]^{2+}$ ions. This result is the first demonstration of CE-ESITOF in the analysis of harmful microcystins. The CE-UV and CE-MS results described in this project have been shown to be a rapid, useful, and sensitive assay for determining microcystins in environmental samples that may cause human illness or even death. In the future study, the methodologies could be applied on the detection of other 
cyanotoxins such as nodularin, anatoxin, and cylindrospermopsin. The methods could be tested on portable CE devices and on the microfluidic devices. 


\section{References}

1. Andersen, R. A. (1992) Diversity of eukaryotic algae, Biodivers. Conserv. 1, 267292.

2. Fleurence, J. (1999) Seaweed proteins: biochemical, nutritional aspects and potential uses, Trends Food Sci. Technol. 10, 25-28.

3. Hallegraeff, G. M. (1993) A review of harmful algal blooms and their apparent global increase*, Phycologia 32, 79-99.

4. van Apeldoorn, M. E., van Egmond, H. P., Speijers, G. J. A., and Bakker, G. J. I. (2007) Toxins of cyanobacteria, Mol. Nutr. Food Res. 51, 7-60.

5. Jurczak, T., Tarczyñska, M., Karlsson, K., and Meriluoto, J. (2004) Characterization and Diversity of Cyano- bacterial Hepatotoxins (Microcystins) in Blooms from Polish Freshwaters Identified by Liquid ChromatographyElectrospray Ionisation Mass Spectrometry, Chromatographia 59, 571-578.

6. Wang, X., Parkpian, P., Fujimoto, N., Ruchirawat, K. M., DeLaune, R. D., and Jugsujinda, A. (2002) Environmental conditions associating microcystins production to microcystis aeruginosa in a reservoir of Thailand, Journal of Environmental Science and Health, Part A 37, 1181-1207.

7. Ciganovich, E. A. (1999) Field Manual of Wildlife Diseases.

8. Katırcıoğlu, H., Akın, B. S., and Atıcı, T. (2004) Microalgal toxin(s): characteristics and importance, African Journal of Biotechnology 3, 667-674.

9. Yoo, S. R. (1995) Cyanobacterial (Blue-Green Algal) Toxins: A Resource Guide, AWWA Research Foundation and American Water Works Association.

10. Yoshizawa, S., Matsushima, R., Watanabe, M., Harada, K.-i., Ichihara, A., Carmichael, W., and Fujiki, H. (1990) Inhibition of protein phosphatases by microcystis and nodularin associated with hepatotoxicity, J. Cancer Res. Clin. Oncol. 116, 609-614.

11. McElhiney, J., and Lawton, L. A. (2005) Detection of the cyanobacterial hepatotoxins microcystins, Toxicol. Appl. Pharmacol. 203, 219-230.

12. Feurstein, D., Holst, K., Fischer, A., and Dietrich, D. R. (2009) Oatp-associated uptake and toxicity of microcystins in primary murine whole brain cells, Toxicol. Appl. Pharmacol. 234, 247-255.

13. Puerto, M., Pichardo, S., Jos, Á., and Cameán, A. M. (2009) Comparison of the toxicity induced by microcystin-RR and microcystin-YR in differentiated and undifferentiated Caco-2 cells, Toxicon 54, 161-169. 
14. Prieto, A. I., Jos, A., Pichardo, S., Moreno, I., de Sotomayor, M. Á., Moyano, R., Blanco, A., and Cameán, A. M. (2009) Time-dependent protective efficacy of Trolox (vitamin E analog) against microcystin-induced toxicity in tilapia (Oreochromis niloticus), Environ. Toxicol. 24, 563-579.

15. World Health Organization (1998) Guidelines for drinking-water quality, Vol. 2, 2 ed.

16. Pearson, L. A., Moffitt, M. C., Ginn, H. P., and Neilan, B. A. (2008) The Molecular Genetics and Regulation of Cyanobacterial Peptide Hepatotoxin Biosynthesis, Crit. Rev. Toxicol. 38, 847-856.

17. Young, F. M., Thomson, C., Metcalf, J. S., Lucocq, J. M., and Codd, G. A. (2005) Immunogold localisation of microcystins in cryosectioned cells of Microcystis, $J$. Struct. Biol. 151, 208-214.

18. Song, W., de la Cruz, A. A., Rein, K., and O'Shea, K. E. (2006) Ultrasonically Induced Degradation of Microcystin-LR and -RR: Identification of Products, Effect of pH, Formation and Destruction of Peroxides, Environ. Sci. Technol. 40, 3941-3946.

19. Tsuji, K., Naito, S., Kondo, F., Ishikawa, N., Watanabe, M. F., Suzuki, M., and Harada, K.-i. (1994) Stability of microcystins from cyanobacteria: effect of light on decomposition and isomerization, Environ. Sci. Technol. 28, 173-177.

20. MacKintosh, C., Beattie, K. A., Klumpp, S., Cohen, P., and Codd, G. A. (1990) Cyanobacterial microcystin-LR is a potent and specific inhibitor of protein phosphatases 1 and 2A from both mammals and higher plants, FEBS Lett. 264, 187-192.

21. Maynes, J. T., Luu, H. A., Cherney, M. M., Andersen, R. J., Williams, D., Holmes, C. F. B., and James, M. N. G. (2006) Crystal Structures of Protein Phosphatase-1 Bound to Motuporin and Dihydromicrocystin-LA: Elucidation of the Mechanism of Enzyme Inhibition by Cyanobacterial Toxins, J. Mol. Biol. 356, 111-120.

22. Craig, M., Luu, H. A., McCready, T. L., Holmes, C. F. B., Williams, D., and Andersen, R. J. (1996) Molecular mechanisms underlying the interaction of motuporin and microcystins with type-1 and type-2A protein phosphatases, Biochem. Cell Biol. 74, 569-578.

23. Honkanen, R. E., Zwiller, J., Moore, R. E., Daily, S. L., Khatra, B. S., Dukelow, M., and Boynton, A. L. (1990) Characterization of microcystin-LR, a potent inhibitor of type 1 and type 2A protein phosphatases, J. Biol. Chem. 265, 1940119404. 
24. Goldberg, J., Huang, H.-b., Kwon, Y.-g., Greengard, P., Nairn, A. C., and Kuriyan, J. (1995) Three-dimensional structure of the catalytic subunit of protein serine/threonine phosphatase-1, Nature 376, 745-753.

25. Dawson, J. F., and Holmes, C. F. B. (1999) Molecular mechanisms underlying inhibition of protein phosphatases by marine toxins, Front. Biosci. 4, D646-D658.

26. Lee, E. Y. C., Zhang, L., Zhao, S., Wei, Q., Zhang, J., Qi, Z., and Belmonte, E. R. (1999) Phosphorylase phosphatase: new horizons for an old enzyme, Front. Biosci. 4, D270-D285.

27. Xing, Y., Xu, Y., Chen, Y., Jeffrey, P. D., Chao, Y., Lin, Z., Li, Z., Strack, S., Stock, J. B., and Shi, Y. (2006) Structure of Protein Phosphatase 2A Core Enzyme Bound to Tumor-Inducing Toxins, Cell 127, 341-353.

28. Sangolkar, L. N., Maske, S. S., and Chakrabarti, T. (2006) Methods for determining microcystins (peptide hepatotoxins) and microcystin-producing cyanobacteria, Water Res. 40, 3485-3496.

29. Meriluoto, J. (1997) Chromatography of microcystins, Anal. Chim. Acta 352, 277298.

30. Diehnelt, C. W., Peterman, S. M., and Budde, W. L. (2005) Liquid chromatography-tandem mass spectrometry and accurate $\mathrm{m} / \mathrm{z}$ measurements of cyclic peptide cyanobacteria toxins, TrAC, Trends Anal. Chem. 24, 622-634.

31. Pérez, S., and Aga, D. S. (2005) Recent advances in the sample preparation, liquid chromatography tandem mass spectrometric analysis and environmental fate of microcystins in water, TrAC, Trends Anal. Chem. 24, 658-670.

32. Gathercole, P. S., and Thiel, P. G. (1987) Liquid chromatographic determination of the cyanoginosins, toxins produced by the cyanobacterium Microcystis aeruginosa, J. Chromatogr. 408, 435-440.

33. Watanabe, M. M., Kaya, K., and Takamura, N. (1992) Fate of the toxic cyclic heptapeptides, the microcystins, from blooms of microcystis (cyanobacteria) in a hypertrophic labke 1, J. Phycol. 28, 761-767.

34. Kos, P., Gorzo, G., Suranyi, G., and Borbely, G. (1995) Simple and Efficient Method for Isolation and Measurement of Cyanobacterial Hepatotoxins by Plant Tests (Sinapis alba L.), Anal. Biochem. 225, 49-53.

35. Allis, O., Dauphard, J., Hamilton, B., Ni Shuilleabhain, A., Lehane, M., James, K. J., and Furey, A. (2007) Liquid Chromatography-Tandem Mass Spectrometry Application, for the Determination of Extracellular Hepatotoxins in Irish Lake and Drinking Waters, Anal. Chem. 79, 3436-3447. 
36. Diehnelt, C. W., Dugan, N. R., Peterman, S. M., and Budde, W. L. (2005) Identification of Microcystin Toxins from a Strain of Microcystis aeruginosa by Liquid Chromatography Introduction into a Hybrid Linear Ion Trap-Fourier Transform Ion Cyclotron Resonance Mass Spectrometer, Anal. Chem. 78, 501512.

37. Barco, M., Rivera, J., and Caixach, J. (2002) Analysis of cyanobacterial hepatotoxins in water samples by microbore reversed-phase liquid chromatography-electrospray ionisation mass spectrometry, J. Chromatogr. 959, 103-111.

38. Bateman, K. P., Thibault, P., Douglas, D. J., and White, R. L. (1995) Mass spectral analyses of microcystins from toxic cyanobacteria using on-line chromatographic and electrophoretic separations, J. Chromatogr. 712, 253-268.

39. Murata, H., Shoji, H., Oshikata, M., Harada, K.-I., Suzuki, M., Kondo, F., and Goto, H. (1995) High-performance liquid chromatography with chemiluminescence detection of derivatized microcystins, J. Chromatogr. 693, 263-270.

40. Zhao, Y.-Y., Hrudey, S., and Li, X.-F. (2006) Determination of Microcystins in Water Using Integrated Solid-Phase Microextraction with Microbore HighPerformance Liquid Chromatography_Electrospray Quadruple Time-of-Flight Mass Spectrometry, J. Chromatogr. Sci. 44, 359-365.

41. Barco, M., Lawton, L. A., Rivera, J., and Caixach, J. (2005) Optimization of intracellular microcystin extraction for their subsequent analysis by highperformance liquid chromatography, J. Chromatogr. 1074, 23-30.

42. Spoof, L., and Meriluoto, J. (2002) Rapid separation of microcystins and nodularin using a monolithic silica $\mathrm{C}_{18}$ column, J. Chromatogr. 947, 237-245.

43. Gu, C., Lin, L., Chen, X., Jia, J., Wu, D., and Fang, N. (2007) Analysis of microcystins by capillary high performance liquid chromatography using a polymethacrylate-based monolithic column, J. Sep. Sci. 30, 2866-2873.

44. Meriluoto, J., Kincaid, B., Smyth, M. R., and Wasberg, M. (1998) Electrochemical detection of microcystins, cyanobacterial peptide hepatotoxins, following high-performance liquid chromatography, J. Chromatogr. 810, 226-230.

45. Weinberger, R. (2000) Practical Capillary Electrophoresis, 2 ed., Academic Press.

46. Landers, J. P. (1993) Handbook of Capillary Electrophoresis, CRC Press.

47. Venn, R. F. (2000) Principles and Practice of Bioanalysis, 2 ed., CRC Press. 
48. Khaledi, M. G. (1998) High-Performance Capillary Electrophoresis: Theory, Techniques, and Applications, Wiley.

49. Krivácsy, Z., Gelencsér, A., Hlavay, J., Kiss, G., and Sárvári, Z. (1999) Electrokinetic injection in capillary electrophoresis and its application to the analysis of inorganic compounds, J. Chromatogr. 834, 21-44.

50. Smith, R. D., Barinaga, C. J., and Udseth, H. R. (1988) Improved electrospray ionization interface for capillary zone electrophoresis-mass spectrometry, Anal. Chem. 60, 1948-1952.

51. Olivares, J. A., Nguyen, N. T., Yonker, C. R., and Smith, R. D. (1987) On-line mass spectrometric detection for capillary zone electrophoresis, Anal. Chem. 59, $1230-1232$.

52. Schmitt-Kopplin, P., and Frommberger, M. (2003) Capillary electrophoresis mass spectrometry: 15 years of developments and applications, Electrophoresis 24, 3837-3867.

53. Kašička, V. (2001) Recent advances in capillary electrophoresis of peptides, Electrophoresis 22, 4139-4162.

54. Dolník, V., and Hutterer, K. M. (2001) Capillary electrophoresis of proteins 1999-2001, Electrophoresis 22, 4163-4178.

55. Righetti, P. G., Gelfi, C., and D'Acunto, M. R. (2002) Recent progress in DNA analysis by capillary electrophoresis, Electrophoresis 23, 1361-1374.

56. Wittke, S., Fliser, D., Haubitz, M., Bartel, S., Krebs, R., Hausadel, F., Hillmann, M., Golovko, I., Koester, P., Haller, H., Kaiser, T., Mischak, H., and Weissinger, E. M. (2003) Determination of peptides and proteins in human urine with capillary electrophoresis-mass spectrometry, a suitable tool for the establishment of new diagnostic markers, J. Chromatogr. 1013, 173-181.

57. Liu, Y., Garcia, C. D., and Henry, C. S. (2003) Recent progress in the development of $\mu \mathrm{TAS}$ for clinical analysis, Analyst 128, 1002-1008.

58. Breadmore, M. C., Wolfe, K. A., Arcibal, I. G., Leung, W. K., Dickson, D., Giordano, B. C., Power, M. E., Ferrance, J. P., Feldman, S. H., Norris, P. M., and Landers, J. P. (2003) Microchip-Based Purification of DNA from Biological Samples, Anal. Chem. 75, 1880-1886.

59. Hummert, C., Reichelt, M., Legrand, C., Graneli, E., and Luckas, B. (1999) Rapid clean-up and effective sample preparation procedure for unambiguous determination of the cyclic peptides microcystin and nodularin, Chromatographia 50, 173-180. 
60. Kuhn, R., and Hoffstetter-Kuhn, S. (1992) Chiral separation by capillary electrophoresis, Chromatographia 34, 505-512.

61. Contradi, S., Vogt, C., and Rohde, E. (1997) Separation of Enantiomeric Barbiturates by Capillary Electrophoresis Using a Cyclodextrin Containing Run Buffer, J. Chem. Educ. 74, 1122.

62. Maruszak, W., Schmid, M., Gübitz, G., Ekiert, E., and Trojanowicz, M. (2004) Separation of Enantiomers by Capillary Electrophoresis Using Cyclodextrins, In Chiral Separations (Gübitz, G., and Schmid, M., Eds.), pp 275-289, Humana Press.

63. Majid, E., Male, K. B., Tzeng, Y.-M., Omamogho, J. O., Glennon, J. D., and Luong, J. H. T. (2009) Cyclodextrin-modified capillary electrophoresis for achiral and chiral separation of ergostane and lanostane compounds extracted from the fruiting body of Antrodia camphorata, Electrophoresis 30, 1967-1975.

64. Chen, L., Dionysiou, D. D., and O'Shea, K. (2011) Complexation of Microcystins and Nodularin by Cyclodextrins in Aqueous Solution, a Potential Removal Strategy, Environ. Sci. Technol. 45, 2293-2300.

65. Sirén, H., Jussila, M., Liu, H., Peltoniemi, S., Sivonen, K., and Riekkola, M.-L. (1999) Separation, purity testing and identification of cyanobacterial hepatotoxins with capillary electrophoresis and electrospray mass spectrometry, J. Chromatogr. 839, 203-215. 